\title{
Öber das Jecorin und andere lecithinartige Produkte der Pferdeleber.
}

\author{
Von \\ A. Baskoff. \\ (Aus dem chemischen Laboratorium d. K. Instituts für experimentelle Medizin zu \\ St. Petersburg.)
}

(Der Redaktion zugegangen am 2. September 1908.)

Unter den lecithinartigen Produkten der Pferdeleber ist es das Jecorin, das schon seit langer Zeit ein großes Interesse der Forscher erregt hatte. Das Jecorin ist bekanntlich von Drechsel ${ }^{1}$ ) entdeckt, der es zuerst aus Pferdeleber, nachher aus der Leber des Delphins darstellte. Zu diesem Zwecke wurde die Pferdeleber in der Hackmaschine zerkleinert und zweimal mit absolutem Alkohol extrahiert. Die vereinigten Alkoholextrakte wurden bei $40-50^{\circ}$ eingedampft, bis ein halbflüssiger, gelblichbrauner Rückstand zurückblieb. Dieser Rückstand wurde mit 2-3 Volumen absoluten Alkohols durchgeschüttelt, wobei der größte Teil des Rückstandes unter Hinterlassung gelblicher, schmieriger Klumpen, die beim Stehen sich zusammenballten, sich löste, und dieser letztgenannte Rückstand wurde nochmals mit Alkohol, bis derselbe nichts mehr aufnahm, behandelt und darauf in Äther gelöst. Zur ätherischen Lösung wurden 3 Volumen absoluten Alkohols hinzugesetzt. Dabei entstand ein gelbbrauner Niederschlag, welcher wiederum in Äther gelöst und mit Alkohol niedergeschlagen wurde. Diese Operation wurde $6-8 \mathrm{mal}$ wiederholt, wodurch Drechsel die Substanz rein zu bekommen glaubte. Zuletzt wurde der Niederschlag abfiltriert und im Vakuum über Schwefelsäure getrocknet. Er stellte eine gelbbraune Masse dar, die

1) Drechsel, Journal f. prakt. Chemie, Bd. XXXIII, S. 425, 1886. Zeitschrift f. Biol., Bd. XXXIII, 1896. 
sich leicht $\mathrm{zu}$ einem gelblichweißen Pulver zerreiben ließ. Dieser Substanz hat Drechsel den Namen Jecorin gegeben. Die Analysen ergaben folgende Resultate:

$$
\begin{aligned}
& \mathrm{G}=51,32-51,64 \% ; \mathrm{H}=8,11-8,25 \% ; \mathrm{N}=2,86 \% \\
& \mathrm{~S}= 1,42-1,47 \% ; \mathrm{P}=3,2-3,7 \% ; \mathrm{Na}=2,72 \% \\
& \mathrm{O}= 30,1 \% . \\
& \text { Daraus berechnet Drechsel für das Jecorin die Formel: } \\
& \mathrm{C}_{105} \mathrm{H}_{185} \mathrm{~N}_{5} \mathrm{SP}_{3} \mathrm{Na}_{3} \mathrm{O}_{46} .
\end{aligned}
$$

Das gut getrocknete Jecorin ist unlöslich in Alkohol und ebenso im wasserfreien Äther; die Lösung im Äther erfolgt leicht, wenn man etwas Wasser hinzufügt. Daraus schließt Drechsel, daß Jecorin eine Hydratform bildet, die im Äther löslich ist, und sein Hydratwasser beim Stehen über $\mathrm{H}_{2} \mathrm{SO}_{4}$ verliert, wodurch es äußerst schwer in Äther löslich wird. Das Jecorin ist sehr hydroskopisch und in der Luft zerfließbar. In Wasser löste es sich nach vorhergehender Quellung. Durch konzentrierte Salzlösungen wurde die wässerige Lösung gefällt. Essigsaures Kupferoxyd und salpetersaures Silberoxyd fällten die Lösung gleichfalls. Die Niederschläge lösten sich auf Zusatz von Jecorinlösung. Diese Lösungen waren stark opalisierend. Die silberhaltige Lösung wurde durch etwas Ammoniak völlig klar und färbte sich beim Kochen portweinrot. Versetzte man die $\mathrm{Cu}$-haltige Lösung mit einigen Tropfen Natronlauge, so wurde die Lösung blau und ganz klar. Sie schied beim Kochen rotes Kupferoxydul aus; dasselbe geschah beim Kochen einer Jecorinlösung mit Fehlingscher Lösung. Beim Kochen der Jecorinlösung mit Lauge entweichen übelriechende basische Dämpfe und nach dem Erkalten erstarrt die Flüssigkeit zu einem Seifenleim. Beim Kochen der Jecorilösung mit Salzsäure entstand ein flockiger Niederschlag, der von Drechsel als Stearinsäure erkannt wurde.

Nach Drechsel wurde das Jecorin von Baldi ${ }^{1}$ ) aus Kaninchen- und Hundeleber etc. dargestellt. Zur Darstellung des Jecorins gebrauchte Baldi die Drechselsche Methode mit dem Unterschied, daß er nach dem Abdampfen des Alkohol-

1) Arch. f. Anat. u. Physiol., phys. Abt., 1887, Suppl., S. 100. 
extraktes den Rückstand direkt im Äther, ohne vorhergehendem Durchschütteln mit Alkohol, löste und durch Alkohol ausfällte. Sein Jecorin löste sich gut in Wasser und gab in der Kälte keine Trübung beim Zusatz von konzentrierter Salzsäure, worin Baldi die Reinheit des Präparats zu erblicken glaubt.

Er erhielt bei der Analyse folgende Werte:

$\mathrm{C}=46,88-46,89 \% ; \mathrm{H}=7,81-8,09 \% ; \mathrm{N}=4,36$ $-4,88 \% ; \mathrm{S}=2,14-2,70 \% ; \mathrm{P}=2,29-2,75 \%$; $\mathrm{Na}=5,72 \%$.

Die wichtigsten Aufschlüsse über die chemische Konstitution des Jecorins sind von Manasse ${ }^{1}$ ) erbracht worden. Er stellte aus Pferdeleber Jecorin nach der Drechselschen Methode dar und wies in ihm die Spaltungsprodukte des Lecithins: Fettsäuren, Cholin, Glycerin und Phosphorsäuren nach, nachdem er das Jecorin nach üblichem Verfahren durch Kochen mit Barytlösung zersetzt hatte. Die frei abgeschiedenen Fettsäuren bildeten Krystalle, die bei $58-60^{\circ}$ schmolzen. In der alkoholischen Lösung der Zersetzungsprodukte bildete sich nach Hinzufügen der Platinchloridlösung ein gelber Niederschlag, der als salzsaures Neurinplatinchlorid anerkannt wurde, und endlich in der wässerigen Lösung wurde Glycerinphosphorsäure nachgewiesen, nachdem der Abdampfungsrückstand deutlich Phosphorreaktion aufwies.

Auch die reduzierende Substanz des Jecorins wurde von Manass e näher bestimmt. Zu diesem Zwecke wurde die Jecorinlösung mit $2^{1 / 2} \%$ iger Schwefelsäure gekocht; hierbei schied sich aus der Lösung eine harzige Masse ab, welche abfiltriert wurde. Das Filtrat wurde mit salzsaurem Phenylhydrazin und essigsaurem Natron nach der Fischerschen Vorschrift behandelt; dabei schieden sich Osazonkrystalle aus, die bei 203-204 0 schmolzen. Es war also ein Glykosazon, und damit war das Vorhandensein der Glykose bewiesen.

Durch diese Versuche zeigte Manasse, daß Jecorin einen Lecithinkomplex und außerdem noch Glykose enthalte.

Manasse stellte außerdem Jecorin aus Nebennieren dar und fand in ihm:

1) Manasse, Diese Zeitschrift, Bd. XX, S. 478, 1895.

Hoppe-Seyler's Zeitschrift f. physiol. Chemie. LVII. 


$$
\begin{aligned}
& \mathrm{C}=41,43 \% ; \mathrm{H}=7,16 \% ; \mathrm{S}=1,8 \% ; \mathrm{P}=4,4 \% ; \\
& \mathrm{N}=0,3 \% .
\end{aligned}
$$

Dieses Jecorin aus Nebennieren reduzierte niemals Kupfer in alkalischer Lösung. Erst nachdem die Jecorinlösung mit $2^{1 / 2} \%$ iger Schwefelsäure im zugeschmolzenen Rohr 5 Stunden auf $130^{\circ}$ erhitzt wurde, reduzierte die Lösung deutlich. Folglich ist die Glykose des Nebennierenjecorins anders gebunden als die des Leberjecorins.

Die nächsten Autoren, die sich mit Jecorin beschäftigten, haben ihr Interesse vorwiegend der von Baldi festgestellten Tatsache zugewendet, nämlich dem Jecoringehalt des Blutes.

0 tto $^{1}$ ) hat nachgewiesen, daß neben gärungsfähiger Dextrose noch andere gärungsfähige reduzierende Substanzen im Blute vorkommen. Mit dieser reduzierenden Substanz im Blute haben Jacobsen, ${ }^{2}$ ) Henriques, ${ }^{3}$ ) Bing ${ }^{4}$ ) sich beschäftigt, dieselbe als Jecorin erkannt und die Behauptung aufgestellt, daß der größte Teil des Blutzuckers nicht als solcher, sondern an Lecithin gebunden, als Jecorin im Blute kreist.

Nachdem dann Bing gezeigt hatte, daß durch Zusammenbringen von Lecithin und Glykose Lecithinzucker entsteht, galt es umsomehr als ausgemacht, daß Jecorin nichts anderes sei, als eine Verbindung von Lecithin und Glykose.

Bing hat die Lecithinglykose auf folgende Weise dargestellt:

Er löste in alkoholischen Lecithinlösungen verschiedene Mengen von Glykose, dampfte den Alkohol bei $42^{\circ}$ ein und löste den Rückstand in wasserhaltigem Äther. Wenn im Verhältnis zur Glykosemenge viel Lecithin vorhanden war, so löste sich der Rückstand vollständig klar in Äther; wenn jedoch viel Glykose zugegen war, so blieb ein weißer Niederschlag zurück. Der Abdampfungsrückstand der ätherischen Lösung reduzierte Fehlingsche Lösung; es war also Glykose in die

1) Otto, Pflügers Archiv, Bd. XXXV, 1885.

2) Jakobsen, Zentralbl. f. Physiol., 1882, und Skand. Archiv für Physiol., Bd. VI, S. 262, 1895.

s) Henriques, Diese Zeitschrift, Bd. XXIII, S. 244, 1897.

4) Bing, Skandinav. Archiv f. Physiol., Bd. IX, S. 356, 1896, und Zentralblatt f. Physiol., Bd. XII, S. 209, 1898. 
Atherlösung übergegangen. Durch Zusatz von Alkohol zu der ätherischen Lösung entstand eine Fällung, die durch den Überschuß ganz oder teilweise wieder aufgelöst wurde. Umgekehrt fand Bing, daß der Lecithinzucker aus einer Alkohollösung durch Äther gefällt wird.

Da nun das Jecorin ganz ähnliche Löslichkeitsverhältnisse Alkohol und Äther gegenüber zeigt, so kommt Bing zum Schluß, daß Jecorin und Lecithinglykose identische oder wenigstens einander sehr nahestehende Verbindungen seien. Schwefel und Natrium, die stets im Jecorin zu finden sind, rühren, seiner Ansicht nach, lediglich von Verunreinigungen der Präparate her.

Eingehender wurde die Lecithinglykose von Mayer ${ }^{1}$ ) untersucht. Während Bing seine Versuche ausschließlich mit dem Ätherauszuge des ursprünglichen alkoholischen Abdampfungsrückstandes und nicht mit der isolierten Lecithinglykose angestellt hatte, beschäftigte sich Mayer mit der Lecithinglykose, die aus den Ätherauszügen durch Alkohol gefällt wurde.

Durch eine Reihe von Versuchen fand Mayer, daß der alkoholische Abdampfungsrückstand sich am besten in Äther oder Benzol löste, wenn man Lecithin mit Glykose zur Darstellung der Lecithinglykose im Verhältnis von 5:2 zusammenbringt. Aus der Benzol- ev. Ätherlösung wurde Lecithinglykose Jurch absoluten Alkohol gefällt, abfiltriert, wiederum im Benzol gelöst und zum zweitenmal durch Alkohol gefällt; darauf wurde der Niederschlag abfiltriert und im Vakuumexsikkator getrocknet. Auf diese Weise erhält man ein fast farbloses Pulver, das schnell bei Berührung mit Luft Wasser anzieht, wobei es sich bräunt und schließlich verschmiert. Die Substanz löst sich im Wasser zu einer opaken Flüssigkeit, ist aber, solange sie noch feucht ist, in Äther unlöslich. Die so dargestellte Lecithinglykose enthielt 84,50\% Traubenzucker.

Die Elementaranalyse der Lecithinglykose und des benutzten Lecithins ergaben folgende Resultate; des Vergleiches halber sind hier auch die Zahlen für Glykơse angeführt:

1) Mayer, Biochemische Zeitschrift, Bd. I, 1906, S. 81. 
A. Baskoff,

\begin{tabular}{c|c|c|c}
\hline \hline & $\begin{array}{c}\text { Lecithinglykose } \\
\%\end{array}$ & $\begin{array}{c}\text { Lecithin } \\
\%\end{array}$ & $\begin{array}{c}\text { Glykose } \\
\%\end{array}$ \\
\hline $\mathrm{H}=$ & 38,7 & 65 & 40 \\
$\mathrm{C}=$ & 9,29 & 10,8 & 6,7 \\
$\mathrm{~N}=$ & 1,09 & 1,8 & - \\
$\mathrm{P}=$ & 0,66 & 3,9 & - \\
$\mathrm{O}=$ & 50,26 & 18,5 & 53,3 \\
\cline { 2 - 4 } & 100,00 & & \\
$\mathrm{P}: \mathrm{N}=1: 3,66$. & &
\end{tabular}

Auf Grund seiner Beobachtungen hält Mayer für möglich, daß es verschiedene Verbindungen der Lecithinglykose gibt, je nach den Mengen Lecithin und Glykose, die man aufeinander wirken läßt. Die Lecithinglykose erweist sich als eine äußerst unbeständige Verbindung; wenn man die trockne Substanz in wasserhaltigem Äther löst, so scheidet sich beim Stehen der Lösung ein Teil des Traubenzuckers ab. Läßt man die ätherische Lösung auf dem Wasserbade verdunsten, so kann die Spaltung eine vollständige sein; denn nimmt man jetzt den Rückstand durch Benzol auf, so gehen nur Spuren von Glykose in Benzol über.

Auf Grund aller seiner Beobachtungen hält Mayer die Behauptung Bings, daß Lecithinglykose eine echte Verbindung ist, für sehr zweifelhaft und nimmt an, daß hier eher eine sogenannte feste Lösung vorliege, daß beim Eindampfen alkoholischer Lecithin-Traubenzuckerlösungen die beiden Substanzen sich in ihren Löslichkeitsverhältnissen derart beeinflussen, daß Glykose äther- und benzollöslich wird, aber nicht die Gesamtmenge derselben in engere Relation zum Lecithin trete.

Mayer stellte ferner Jecorin aus Pferdeleber nach der Drechselschen Methode dar.

Die Elementaranalyse des Jecorins gab folgende Zahlen: $\mathrm{C}=55,79 \% ; \mathrm{H}=4,44 \% ; \mathrm{N}=2,59 \% ; \mathrm{S}=1,17 \%$; $\mathrm{P}=1,37 \%, \mathrm{Na}=3,54 \%$.

Mayer hat die Reduktionsfähigkeit des Jecorins untersucht und dabei gefunden, daß bei direkter Behandlung des Jecorins mit Fehlingscher Lösung die Reduktion erheblich 
geringer ist, als nach vorheriger Bearbeitung der Jecorinlösung mit $\mathrm{H}_{2} \mathrm{SO}_{4}$. So zeigte das Jecorin bei direkter Behandlung mit Fehlingscher Lösung 10\% Glykose auf; wurde aber das Jecorin zuerst mit $5 \%$ iger $\mathrm{H}_{2} \mathrm{SO}_{4}$ gekocht, so wies es $18,2 \%$ Traubenzucker auf.

Da alle bisher von den verschiedenen Autoren dargestellten Jecorine sehr erhebliche Differenzen in ihrer elementaren Zusammensetzung zeigen, so kommt Mayer zum Schluß, daß das Jecorin keine einheitliche Substanz sein kann, sondern ein Gemenge verschiedener Verbindungen.

$\mathrm{Zu}$ demselben Schluß kommen auch Meinertz und Siegfried und Mark.

Meinert $\left.z^{1}\right)$ stellte ebenfalls Jecorin aus Pferdeleber nach der Drechselschen Methode dar. Der Ätherextrakt der Leber wurde bis zur Trockene abgedampft, und der Rückstand direkt in Äther gelöst und mit Alkohol gefällt, der Niederschlag von neuem in Äther gelöst und mit Alkohol gefällt. Der nach wiederholtem Umfällen getrocknete Körper war hellgelb, in Äther nur nach Zusatz einer geringen Menge Wasser löslich und quoll in Wasser zur opalisierenden Lösung. An diesem Jecorin versuchte Meinertz durch wiederholtes Ausfällen mit Alkohol eine Abspaltung der reduzierenden Substanz zu bewirken; dabei beobachtete er, daß durch wiederholte Ausfällung keine merkbare Abnahme des Reduktionsvermögens eintrat; der Prozentgehalt in reduzierender Substanz war nach der 4. und 5. Ausfällung etwa der gleiche wie am Anfange rund 14\%.

Sieg fried und $\mathrm{Mark}^{2}$ ) stellten ebenfalls das Jecorin aus Pferdeleber nach der Drechselschen Methode dar, nur wurde das aus der ätherischen Lösung gefällte Jecorin anhaltend mit absolutem Alkohol dekantiert und dann in einem zu diesem Zwecke konstruierten Apparate, in den durch große Flächen Kaliumcarbonat die Luft trocken gehalten wurde, filtriert. Ob das Jecorin von den genannten Autoren durch Lösen im Äther und Ausfällen durch Alkohol gereinigt wurde, ist aus dem Berichte nicht zu ersehen. Die Analyse des Jecorins gab folgende Zahlen:

1) Meinertz, Diese Zeitschrift, Bd. XLVI, S. 376.

2) Siegfried und Mark, Diese Zeitschrift, Bd. XLVI, S. 492. 


$$
\begin{aligned}
& \mathrm{C}=39,7 \% ; \mathrm{H}=6,4 \% ; \mathrm{N}=5,2 \% ; \mathrm{P}=1,9 \% ; \\
& \mathrm{S}=2,2 \% ; \mathrm{Na}=5,9 \% ; \text { Asche } 15,7 \%
\end{aligned}
$$

$\mathrm{Zu}$ meinen Untersuchungen über die lecithinartigen Produkte der Pferdeleber wurde ich durch Frau N. O. Sieber angeregt, die mir bei der Ausführung der Arbeit stets liebenswürdigen Beistand leistete.

\section{Versuch Nr. I.}

$\mathrm{Zu}$ meinen Untersuchungen der lecithinartigen Produkte der Pferdeleber herantretend, suchte ich zuerst Jecorin nach der Drechselschen Methode darzustellen.

$\mathrm{Zu}$ diesem Zwecke wurde die Pferdeleber auf der Fleischhackmaschine in kleine Stücke zerschnitten und darauf mit 2-3 Volumen absoluten Alkohols in großem Gefäß bei gewöhnlicher Temperatur extrahiert. Am nächsten Tage wurde die gelblich gefärbte alkoholische Lösung abgegossen, die Lebersubstanz auf einer Preßmaschine von der alkoholischen Lösung abgepreßt, wiederum zerrieben und mit einer neuen Menge absoluten Alkohols begossen. Der Alkohol färbte sich wiederum gelb; nach einigen Tagen wurde darauf die Lösung abgegossen und filtriert. Die vereinigten Alkoholextrakte wurden in Vacuo bei $40^{\circ}$ bis zur Trockene abgedampft und hinterließen einen schmierigen hellgelbbraunen Rückstand.

Dieser Rückstand wurde mit absolutem Alkohol durchgeschüttelt, dabei färbte sich der Alkohol gelb (durch Auflösen von Lecithin) und es hinterblieb ein gelblicher flockiger, beim Stehen sich stark zusammenballender Rückstand, welcher wiederholt mit neuen Mengen absoluten Alkohols durchgeschüttelt wurde, bis der Alkohol sich nicht mehr färbte. Letztgenannter Rückstand wurde in Äther gelöst, wobei der größere Teil sich löste, mitHinterlassen eines gelblichen Rückstandes. Dieätherische Lösung, die erst nach 1 tägigem Stehen sich klar filtrieren ließ, wurde darauf mit dem 2 fachen Volumen absoluten Alkohols gefällt. Sogleich entstand ein braungelber flockiger Niederschlag, der sich bald zusammenballte und niedersetzte. Dieser Niederschlag ist, wie man gewöhnlich annimmt, das Jecorin. Das auf diesem Wege erhaltene Jecorin war stellenweise mit 
einer braunen Substanz gemischt. Deshalb wurde es zu seiner Reindarstellung in Äther gelöst, wobei wiederum ein Teil ungelöst blieb, und die Lösung nach Abfiltrieren wiederum mit Alkohol gefällt. Diese Operation wurde $4-5$ mal wiederholt. Schließlich wurde der Niederschlag abfiltriert und im Vakuumexsikkator über Schwefelsäure getrocknet. Es bildete sich eine harte spröde Masse, die sich leicht zu einem hellgelben Pulver zerreiben ließ. Diese Substanz zeigte alle von Drechsel und anderen Autoren für das Jecorin angegebenen Merkmale.

Es war unlöslich in Alkohol und löste sich im Äther erst nach Zusatz von etwas Wasser. In Wasser löste es sich nach vorhergehendem Aufquellen, zu einer trüb opalisierenden Lösung. Die Lösung färbte sich nach Zusatz von Silbernitrat und Ammoniak beim Kochen portweinrot und reduzierte Fehlingsche Lösung. Die reduzierende Substanz ließ sich außer durch Kochen mit Fehlingscher Lösung auch durch Barfoeds Reagens (essigsaures Kupferoxyd) durch die Silberspiegelprobe und die Vergärung nachweisen. Das Almèn-Nylandersche Reagens dagegen gab niemals eine Reaktion, es entstand keine Schwärzung durch Reduktion des Wismutoxydes, nach Stehen gelatinierte jedoch die Lösung.

Aus der Leber, die $4500 \mathrm{~g}$ wog, wurde nur $3,5 \mathrm{~g}$ Jecorin erhalten.

Die Analyse der Substanz gab folgende Zahlen (S. 424):

Zum Vergleich sind in der Tabelle Analysenzahlen aller bisher dargestellten Jecorine angeführt.

Elementaranalyse: 1 . $0,2454 \mathrm{~g}$ Substanz gaben $0,1574 \mathrm{~g}_{\mathbf{2}} \mathrm{O}$ $=7,18 \% \mathrm{H}$ und $0,4524 \mathrm{~g} \mathrm{CO}_{2}=50,23 \% \mathrm{C}$. $=50,50 \% \mathrm{C}$.

2. $0.185 \mathrm{~g}$ Substanz gaben $0,1225 \mathrm{~g} \mathrm{H}_{2} \mathrm{O}=7,41 \% \mathrm{H}$ und $0,3422 \mathrm{~g} \mathrm{CO}_{2}$

Kjeldahlbestimmung: 0,2002 g Substanz verbrauchten $4,475 \mathrm{ccm}$ $1 / 10-\mathrm{N}^{-\mathrm{H}_{2}} \mathrm{SO}_{4}$ à $0,00139714 \mathrm{~g} \mathrm{~N}=3,12 \mathrm{~N}$.

Phosphorbestimmung nach Woy: 0,1238 g Substanz gaben $0,2081 \mathrm{~g}^{\mathrm{MoO}} \mathrm{P}_{2} \mathrm{O}_{5}=2,89 \% \mathrm{P}$.

Schwefel- und Chlorbestimmung nach Carius: 0,2412 g Substanz gaben $0,03199 \mathrm{~g} \mathrm{BaSO}_{4}$, d. h. $0,00439304 \mathrm{~g} \mathrm{~S}=1,82 \% \mathrm{~S}$, und $0,00436 \mathrm{~g} \mathrm{AgCl}$, d. h. $0,0012016107 \mathrm{~g} \mathrm{Cl}=0,49 \% \mathrm{Cl}$.

Aschebestimmung: 0,6513 g Substanz gaben 0,0833 g Asche $=12,79 \%$. 


\begin{tabular}{|c|c|c|c|c|c|c|c|}
\hline & $\begin{array}{l}\text { Das von } \\
\text { mir aus } \\
\text { Pferde- } \\
\text { leber } \\
\text { dar- } \\
\text { gestellte } \\
\text { Jecorin } \\
\text { Nr. } 1 \\
\%\end{array}$ & $\begin{array}{c}\text { Drechsels } \\
\text { Jecorin } \\
\text { aus } \\
\text { Pferdeleber } \\
\%\end{array}$ & $\begin{array}{c}\text { Mayers } \\
\text { Jecorin } \\
\text { aus } \\
\text { Pferde- } \\
\text { leber } \\
\%\end{array}$ & $\begin{array}{c}\text { Sieg- } \\
\text { fried } \\
\text { und } \\
\text { Marks } \\
\text { Jecorin } \\
\text { aus } \\
\text { Pferde- } \\
\text { leber } \\
\%\end{array}$ & $\begin{array}{c}\text { Baldis } \\
\text { Jecorin } \\
\text { aus } \\
\text { Hundeleber } \\
\%\end{array}$ & $\begin{array}{c}\text { Ma- } \\
\text { nasses } \\
\text { Jecorin } \\
\text { aus } \\
\text { Neben- } \\
\text { nieren } \\
\%\end{array}$ & $\begin{array}{c}\text { Bier- } \\
\text { nadskys }{ }^{1} \text { ) } \\
\text { Jecorin } \\
\text { aus } \\
\text { Knochen- } \\
\text { mark } \\
\text { des } \\
\text { Hundes } \\
\%\end{array}$ \\
\hline G & 50,39 & $51,32-51,64$ & 55,79 & 39,7 & $|46,88-46,89|$ & 41,45 & 48,63 \\
\hline $\mathrm{H}$ & 7,29 & $8,11-8,25$ & 4,14 & 6,4 & $7,81-8,09$ & 7,1 & 7,68 \\
\hline$N$ & 3,12 & 2,86 & 2,59 & 5,2 & $4,36-4,88$ & - & 2,67 \\
\hline $\mathrm{P}$ & 2,89 & $3,2-3,7$ & 1,37 & 1,9 & $2,29-2,75$ & 4,4 & 2,88 \\
\hline$S$ & 1,82 & $1,42-1,47$ & 1,17 & 2,2 & $2,14-2,7$ & 1,8 & $1, \tilde{a} 7$ \\
\hline $\mathrm{Na}$ & 2,87 & $2,72 \quad-$ & 3,54 & 5,9 & $4,36-4,88$ & - & - \\
\hline $\mathrm{Cl}$ & 0,49 & fehlt & - & - & - & - & - \\
\hline Asche & 12,79 & 12,09 & - & - & - & - & - \\
\hline$P: N$ & & $1: 1,8$ & $1: 4,19$ & $1: 6,08$ & $1: 3,87$ & - & $1: 2,04$ \\
\hline
\end{tabular}

$\mathrm{Na}$-Bestimmung in der Asche durch Wägung des Natriumsulfats, nachdem die Phosphorsäure durch Eisenchlorid gefällt und entfernt wurde: $0,6341 \mathrm{~g}$ Substanz gaben $0,0563 \mathrm{~g} \mathrm{Na}_{2} \mathrm{SO}_{4}=0,0182378 \mathrm{~g} \mathrm{Na}$ $=2,87 \% \mathrm{Na}$.

Aus der Tabelle ersieht man, daß alle Jecorine erhebliche Differenzen in ihrer elementaren Zusammensetzung aufweisen, wobei die Analysenzahlen nicht nur für die absoluten Werte, sondern auch für das prozentuale Verhältnis recht wesentlich von einander abweichen. Das von mir dargestellte Jecorin ist dem Drechselschen Jecorin am nächsten, von dem es im Vergleich zu den Jecorinen anderer Autoren nur unbedeutend abweicht. Der Grund dafür liegt darin, daß ich bei der Darstellung des Jecorins streng die Angaben Drechsels befolgte.

Abweichend von Drechsel, der bei der Verbrennung des Jecorins nach Carius kein Chlor gefunden hatte (es bildete sich bei Drechsel nach Verbrennen im zugeschmolzenen Rohr kein Niederschlag mit Silbernitrat), habe ich dagegen in meinem Jecorin $0,49 \% \mathrm{Cl}$ bestimmen können. Das Verhältnis des

1) W. Biernadsky, Dissertation. Petersburg 1908, J. 
Über Jecorin und andere lecithinartige Produkte der Pferdeleber. 405

Phosphors zu Stickstoff wie $1: 2,38$ ist bei meinem Jecorin dem des Drechselschen $(1: 2,8)$ ziemlich nahe. Bei später dargestellten Jekorien habe ich dieses Verhältnis wie $1: 2$ gefunden.

Zur Traubenzuckerbestimmung gebrauchte ich Allihns Methode (Wägung des reduzierten Kupferoxyduls in Röhrchen). Diese Methode eignet sich bei den Glykosebestimmungen im Jecorin vor allen anderen Methoden am besten. Nur muß man bei der Reduktion der Fehlingschen Lösung auf starke Verdünnung achten, da widrigenfalls beim Kochen leicht ein Niederschlag entsteht, der den Zersetzungsprodukten des Jecorins seinen Ursprung verdankt.

$\mathrm{Da}$ von Mayer angegeben wurde, daß das Jecorin verschiedenen Traubenzuckergehalt aufweist, je nachdem die Glykose im Jecorin nach oder ohne vorhergehende Behandlung mit Schwefelsäure bestimmt wurde, habe ich die Glykosebestimmungen in meinem Jecorin das eine Mal ohne vorhergehende Schwefelsäurebehandlung ausgeführt, das andere Mal, nachdem die Jecorinlösung mit $5 \%$ iger $\mathrm{H}_{8} \mathrm{SO}_{4}$ ca. ${ }^{1 / 2}$ Stunde gekocht wurde. Hierbei erhielt ich immer Resultate, die nur wenig (um $0,4-0,6 \%$ ) von einander abwichen. Dabei achtete ich stets darauf, daß die Jecorinlösung mit der Fehlingschen Lösung nicht weniger als 3 Minuten gekocht wurde.

Jecorin Nr. I

ohne Schwefelsäurebehandlung

mit Schwefelsäurebehandlung

1. $13,61 \%$ Glykose

2. $14,01 \%$, $14,35 \%$ Glykose $14,40 \%$ >

1. $0,0764 \mathrm{~g}$ Substanz gaben $0,0188 \mathrm{~g} \mathrm{Cu}=0,0104 \mathrm{~g}$ Glykose $=13,61 \%$

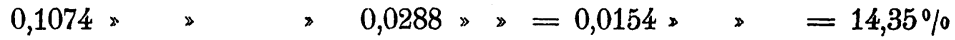

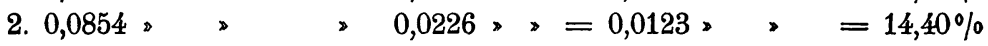
0,1213 > > 0,032 > > $=0,017$ > > $=14,01 \%$

$\mathrm{Zu}$ einem ähnlichen Resultat ist Jakobsen ${ }^{1}$ ) gekommen. Dieser Autor hat das Reduktionsvermögen des Jecorins sowohl ohne wie nach Behandlung mit $\mathrm{H}_{2} \mathrm{SO}_{4}$ untersucht und hierbei gefunden, daß die Reduktion in einigen Fällen beim Kochen mit Säure zunahm, in andern Fällen unverändert blieb. Er spricht daher die Vermutung aus, daß die verschiedene Reduktion vor und nach der Invertierung mit Säure von dem

1) Jakobsen, Skandinav. Archiv für Physiol., Bd. VI, S. 262. 
Umstande herrühre, daß das Jecorin mitunter bei der Titrierung mit Sachscher Lösung unvollständig gespalten wird, während die Säure es vollständig tut. Ich meinerseits habe bemerkt, daß die Reduktion der Fehlingschen Lösung vollständig erst beim längeren Kochen der Lösung zustande kommt.

Bei dem zweiten, aus anderer Pferdeleber stammenden, auf eben demselben Wege dargestellten Jecorinpräparate(Jecorin $\mathrm{Nr}$. II) habe ich 15,12\% Glykose gefunden.

$0,1359 \mathrm{~g}$ Substanz gaben (nach vorhergehender $\mathrm{H}_{2} \mathrm{SO}_{4}$-Behandlung) $0,0395 \mathrm{~g} \mathrm{Cu}=0,02065 \mathrm{~g}$ Glykose $=15,12 \%$.

Die nächsten weiter angeführten Jecorine enthielten im Mittel $14 \%$ Glykose. Diese Tatsache stimmt mit der Angabe Meiner tzs überein, daß alle von ihm nach der Drechselschen Methode aus Pferdeleber hergestellten Jecorine ca. 14\% Glykose enthielten.

Übereinstimmend mit Meinertz habe auch ich gefunden, daß diese Prozentzahl unabhängig ist von der Anzahl der vorgenommenen Auflösungen im Äther und Ausfällungen mit Alkohol; wurden diese Operationen 4,5 oder 6 mal vorgenommen, überall erhielt ich ein Präparat, das ca. 14\% Glykose aufwies. Jedoch direkt nach der ersten oder zweiten Ausfällung analysiert, enthielt das Jecorin etwas mehr als $14 \%$ Glykose.

$\mathrm{Da}$ nun das Jecorin ein lecithinhaltiger Körper ist, suchte ich, um das Verhältnis von Jecorin zu Lecithin aufzuklären, ferner aus dem Alkoholextrakte der Pferdeleber Lecithin darzustellen, um es mit Jecorin vergleichen zu können.

Das Jecorin Nr. I wurde, wie oben beschrieben, dargestellt, indem das Alkoholextrakt eindampft und der Rückstand mit Alkohol behandelt wurde, bis derselbe kein Lecithin mehr aufnahm. Der unlöslich gebliebene Anteil wurde in Äther gelöst und mit Alkohol gefällt (Jecorinfällung) und diese Operation 5-6 mal wiederholt, wobei die Ätherlösungen anfangs deutlich gelb gefärbt waren und ebenfalls Lecithin in sich enthielten. Zur Darstellung des Lecithins wurden nun sowohl die erstgenannte Alkohollösung, wie auch alle ätheralkoholischen Mutterlaugen vereinigt und bis zur Trockene abgedampft. Der Rückstand wurde in Äther gelöst, filtriert und zur Lösung wurde ein 4 faches Volumen Aceton hinzugefügt. Es bildete sich ein 
Über Jecorin und andere lecithinartige Produkte der Pferdeleber. 407

klebriger blaßgelber Niederschlag von Lecithin, welcher nach 24 ständigem Stehen abfiltriert, mit Aceton gewaschen, dann wieder in Äther gelöst und mit Aceton gefällt und schließlich in Vacuo über $\mathrm{H}_{2} \mathrm{SO}_{4}$ getrocknet wurde. Das Lecithin wurde als orangebraune klebrige Masse erhalten (Lecithin Nr. I). Die Analyse ergab folgende Zahlen:

\begin{tabular}{ccc} 
& Lecithin Nr. I. & Lecithin Nr. II. \\
$\mathrm{C}=$ & $62,27 \%$ & $63,33 \%$ \\
$\mathrm{H}=$ & $10,39 \%$ & $10,64 \%$ \\
$\mathrm{~N}=$ & $2,67 \%$ & $2,71 \%$ \\
$\mathrm{P}=$ & $3,53 \%$ & $3,44 \%$ \\
$(0)=$ & - & $(19,81 \%)$ \\
\hline $\mathrm{P}: \mathrm{N}=$ & $1: 1,66$ & $1: 1,77$
\end{tabular}

I.

Kjeldahlbestimmung: $0,1253 \mathrm{~g}$ Substanz verbrauchten $2,4 \mathrm{ccm}$ $\mathrm{n} / 10-\mathrm{H}_{2} \mathrm{SO}_{4}$ à $0,00139714 \mathrm{~g} \mathrm{~N}=2,67 \% \mathrm{~N}$.

Phosphorbestimmung nach Woy: 0,2634 g Substanz gaben $0,5896 \mathrm{~g} \mathrm{MoO}_{8} \mathrm{P}_{8} \mathrm{O}_{5}=0,009287308 \mathrm{~g} \mathrm{P}=3,53 \% \mathrm{P}$.

II.

Elementaranalyse: 0,2424 g Substanz gaben $0,5629 \mathrm{~g} \mathrm{CO}_{\mathbf{2}}=$ $63,0 \% \mathrm{C}$ und $0,2305 \mathrm{~g} \mathrm{H}_{8} \mathrm{O}=10,645 \% \mathrm{H}$.

Kjeld a hlb e st im mung: $0,21218 \mathrm{~g}$ Substanz verbrauchten $4,125 \mathrm{ccm}$ $\mathrm{n} / 10-\mathrm{H}_{2} \mathrm{SO}_{4}$ à $0,00139714 \mathrm{~g} \mathrm{~N}=2,716 \% \mathrm{~N}$.

$0,2433 \mathrm{~g}$ Substanz verbrauchten $4,75 \mathrm{ccm} \mathrm{n} / 10-\mathrm{H}_{9} \mathrm{SO}_{4}=2,721 \% \mathrm{~N}$.

Pbosphorbestimmung nach Woy: 0,4968 g Substanz gaben $0,9925 \mathrm{~g} \mathrm{MoO}_{3} \mathrm{P}_{2} \mathrm{O}_{5}=3,443 \% \mathrm{P}$.

Phosphorbestimmung durch Fällung mit Eisenchlorid: $0,42038 \mathrm{~g}$ Substanz gaben 0,08209 g $_{2} \mathrm{O}_{5}=3,333 \%$ P. ${ }^{1}$ )

Das Lecithin Nr. 2 wurde aus dem Lecithin Nr. 1 auf folgende Weise erhalten. Da ich bemerkte, daß das Lecithin Nr. 1 nicht gänzlich in Alkohol sich löste, so wurde es im kalten Alkohol gelöst, dabei blieb ein im Vergleich zu der ganzen Lecithinmenge unbedeutender Teil ungelöst. Dieser Teil löste sich in Äther und ließ sich durch Alkohol fällen, zeigte also die Eigenschaften des Jecorins. Die von dem ungelösten Anteil abfiltrierte alkoholische Lösung wurde abge-

1) Ich habe bemerkt, daß man bei Phosphorbestimmungen durch Fällung mit Eisenchlorid stets etwas kleinere Zahlen bekommt, als bei der Woy-Bestimmung. 
dampft, der Rückstand in Äther gelöst, durch Aceton gefällt, und der Niederschlag getrocknet.

Auf Grund der angeführten Analysenzahlen muß man dem Lecithin der Pferdeleber die Formel $\mathrm{C}_{49} \mathrm{H}_{99} \mathrm{PN}_{2} \mathrm{O}_{11}$ zuschreiben (Molekulargewicht 920).

Zur Bestimmung der Zersetzungsprodukte des Lecithins wurde $3,758 \mathrm{~g}$ in Alkohol gelöst und mit verdünnter Kalilauge gekocht, bis die Lösung nach Zusatz von Wasser ganz durchsichtig war. Nach Abkühlen wurden die Seifen durch verdünnte Salzsäure zerlegt, das Gemenge auf dem Wasserbade erwärmt und nach dem Erkalten die freigewordenen Fettsäuren mit Äther aufgenommen. Der Äther verdunstet, die Säuren getrocknet und gewogen. Es wurden auf diese Weise 63,65\% Fettsäuren gefunden.

$3,758 \mathrm{~g}$ Lecithin gaben 2,3919 g Fettsäuren $=63,65 \%$ Fettsäuren.

Mittels Titrieren der freigemachten Fettsäuren wurde nun auf dem von Erlandsen empfohlenen Wege die Anzahl der Fettsäureradikale im Lecithin bestimmt. Erlands en ${ }^{1}$ ) bestimmt nämlich die Zahl der Fettsäureradikale nach der Formel

$$
\mathrm{x}=\frac{\mathrm{n} \mathrm{M}}{1000 \mathrm{p}}
$$

wo $\mathrm{n}=$ die beim Titrieren der Fettsäuren verbrauchten Anzahl Kubikzentimeter normaler Alkalilösung, $\mathrm{M}=$ das Molekulargewicht der Substanz und $\mathrm{p}=$ die Anzahl Gramm der verseiften Substanz bedeutet.

Zum Titrieren wurden von der ganzen Anzahl der erhaltenen Fettsäuren (2,3919 g) nur 0,5344 g Fettsäuren entnommen. Diese Menge wurde in Alkohol gelöst, die Lösung durch Kochen von Kohlensäure befreit und mit Wasser und Alkohol verdünnt. Das Titrieren wurde mit n/10-Natronlauge und Phenolphthalein als Indikator vorgenommen.

$0,5344 \mathrm{~g}$ Fettsäuren verbrauchten 17,2 ccm n/10-NaHO; der ganzen Fettsäurenmenge entspricht also $76,88 \mathrm{ccm} \mathrm{n} / 10-\mathrm{NaHO}$.

Setzen wir in obige von Erlandsen abgegebene Formel die entsprechenden Zahlenwerte, so bekommen wir:

1) Erlandsen, Diese Zeitschrift, Bd. LI, S. 104. 
Über Jecorin und andere lecithinartige Produkte der Pferdeleber. 409

$$
\mathrm{x}=\frac{\mathrm{n} \mathrm{M}}{1000 \mathrm{p}}=\frac{7688 \times 920}{1000 \times 3,758}=1,91 .
$$

Das Lecithin enthält demgemäß 2 Fettsäureradikale.

Um die Natur der Fettsäuren zu bestimmen, wurden 0,5344 $\mathrm{g}$ freien Säuren in verdünnter Natronlauge gelöst und etwas gekocht, bis die Lösung vollständig klar wurde. Die erhaltenen Natronseifen wurden durch essigsaures Blei gefällt. Der Niederschlag abfiltriert, getrocknet und darauf mehrere Male mit erwärmtem Äther behandelt. Die ätherische Lösung, die ölsaures Blei enthielt, wurde filtriert, mit verdünnter Salzsäure durchgeschüttelt, die ätherische Lösung verdunstet und die zurückgebliebene Ölsäure getrocknet und gewogen: 0,5344 $\mathrm{g}$ freier Fettsäuren gaben $0,289 \mathrm{~g}$ Ölsäure, d. h. ca. $54 \%$.

Somit stellt die Ölsäure eines der Fettsäureradikale dar, die Stearinsäure oder Palmitinsäure die anderen. Die aus ihrer Verbindung mit Blei freigemachte Säure schmolz bei $51^{\circ}$.

2,2073 $\mathrm{g}$ Lecithin wurden in Alkohol gelöst und mit Barytlösung gekocht. Das überschüssige Baryt durch Kohlensäure gefällt und samt den Barytseifen abfiltriert. Der Filterrückstand wurde unter Wasser durch verdünnte Salzsäure zerlegt, darauf etwas gekocht und die aufgeschwommenen Fettsäuren filtriert, mit Wasser gewaschen und darauf in vacuo getrocknet und gewogen.

Es wurden auf diese Weise 62,52\% Fettsäuren gefunden. $2,2073 \mathrm{~g}$ gaben $1,39 \mathrm{~g}$ Fettsäuren $=62,52 \%$.

Die Hüblersche Zahl des Lecithins beträgt 60,57 .

Aus den Zersetzungsprodukten des Lecithins durch Baryt wurde ferner auf bekanntem Wege, durch Fällen mittels Platinchlorid, Cholinplatinchlorid dargestellt. Es krystallisierte aus Wasser in Form orangebrauner hexagonaler Prismen und Nadeln und wies einen Platingehalt von $31,77 \%$ auf (Theorie $31,64 \%$ ).

0,2191 g Substanz gaben 0,00674 g Pt $=31,77 \%$ Pt.

Aus Lecithin Nr. 2 wurde schlieBlich Cd-Lecithinat dargestellt. $\mathrm{Zu}$ diesem Zwecke wurde das Lecithin in Alkohol gelöst und mit alkoholisch gesättigter $\mathrm{CdCl}_{2}$-Lösung gefällt. Nach 24 Stunden wurde der Niederschlag abfiltriert, sorgfältig mit Alkohol gewaschen und in vacuo getrocknet.

Die Analyse gab folgende Resultate: $\mathrm{N}-1,83 \%, \mathrm{P}$ $-2,85 \%, \mathrm{Cd}-14,73 \% ; \mathrm{P}: \mathrm{N}: \mathrm{Cd}=1: 1,42: 1,46$.

Kjeldahlbestimmung: 0,1781 g Substanz verbrauchten $4,75 \mathrm{ccm}$ $\mathrm{n} / 10-\mathrm{H}_{2} \mathrm{SO}_{4}$ à $0,0069857 \mathrm{~g} \mathrm{~N}=1,86 \% \mathrm{~N}$. 
$0,1912 \mathrm{~g}$ Substanz verbrauchten $4,9 \mathrm{ccm} \quad \mathrm{n} / 10-\mathrm{H}_{2} \mathrm{SO}_{4}=1,81 \% \mathrm{~N}$.

Bestimmung nach Woy. 0,2267 g Substanz gaben $0,3817 \mathrm{~g}$ $\mathrm{MoO}_{3} \mathrm{P}_{2} \mathrm{O}_{5}=2,85 \% \mathrm{P}$.

Bestimmung von Cd auf elektrolytischem Wege nach der Methode von Beilstein und Javein: ${ }^{1}$ )

0,2524 g Substanz gaben $0,0454 \mathrm{~g}$ Cd $=14,73 \% \mathrm{Cd}$.

Nach derselben Methode, wie das Lecithin, wurde auch das Jecorin Nr. 1 durch Natronlauge verseift und der Gehalt an Fettsäuren bestimmt.

Es wies $40,75 \%$ Fettsäuren auf.

$0,9480 \mathrm{~g}$ Substanz gaben $0,3866 \mathrm{~g}$ Fettsäuren $=40,75 \%$.

Die Hüblersche Zahl des Jecorins Nr. I betrug 31,25.

\section{Versuch Nr. 2.}

Bei meinem ersten Versuche bemerkte ich, daß, wenn man das Alkoholextrakt der Leber bis zur Sirupkonsistenz eindampft und nachher den Rückstand ohne vorhergehende Behandlung mit absolutem Alkohol (zur Entfernung von Lecithin) direkt in Äther zu lösen sucht, die Lösung keine vollständige ist. Es bildet sich eine sirupartige dunkelrotbraune Substanz, die sich zu Boden setzt. Deshalb verfuhr ich bei meinem zweiten Versuche folgendermaßen. Das Alkoholextrakt wurde bis zur Sirupkonsistenz eingedampft, mit Äther behandelt und das Ganze in einem Scheidetrichter stehen gelassen. Am nächsten Tage bildeten sich 2 deutliche Schichten, die obere, gelbe Ätherlösung und untere, dunkelbraune sirupartige Flüssigkeit. An der Grenze der beiden Schichten sammelte sich ein-gelblichbrauner flockiger Niederschlag, der unlöslich in Äther und Alkohol war und sich nur schwer in Wasser zu einer trüben Flüssigkeit löste. Dieser Niederschlag wurde abfiltriert, die beiden flüssigen Schichten im Scheidetrichter von einander getrennt, und die obere mit Wasser, die untere mit Äther zur Reinigung durchgeschüttelt. Die ätherische Lösung, die das Jecorin und Lecithin in sich enthielt, wurde in einem schmalen Zylinder, der mit $\mathrm{CO}_{2}$ gefüllt war, stehen gelassen. Es bildete sich beim Stehen ein weißlicher Niederschlag, der sich fest S. 131.

1) Beilstein und Javein, Treadwell, Analytische Chemie, Bd. II, 
niedersetzte, und es wurde von ihm die vollständig durchsichtig gewordene ätherische Lösung abdekantiert und filtriert. Die ätherische Lösung wurde eingeengt und es wurde $\mathrm{zu}$ ihr das 3 fache Volumen absoluten Alkohols hinzugefügt. Es entstand in der Lösung eine gelbliche trübe Fällung, die sich sofort zu einem dunkelbraunen sirupartigen Niederschlag niedersetzte. Dieser Niederschlag war das Jecorin. Es wurde nun von ihm nach Abstehen die ätheralkoholische Lösung abgegossen; der Niederschlag in Äther gelöst, in dem er sich, mit Hinterlassung eines minimalen Rückstandes, löste. Die Lösung wurde wiederum mit Alkohol gefällt, und diese Operation noch dreimal wiederholt. Die zweite Fällung war wieder sirupartig, die dritte stellte einen gelblichen flockigen Niederschlag, der sich bald zusammenballte. Nach der fünften Fällung (wenn man nach jeder Ausfällung den Niederschlag auf 1 Tag stehen läßt, so genügen 4-5 Ausfällungen, um die Substanz rein zu bekommen), stellt das Jecorin einen gelblichen Niederschlag, der aus feinen Flocken besteht und sich nicht mehr so zusammenballt, wie bei den ersten Fällungen. Es löst sich nun vollständig in Äther und wird quantitativ von Alkohol gefällt. Nach dem Trocknen im Vakuumexsikkator bildet es eine spröde Masse, die sich zu einem fast weißen Pulver zerreiben läßt. In Wasser löst es sich unter Aufquellen zu einer trüben l,ösung.

Dieses Jecorin Nr. 2a enthielt: $\mathrm{N}=2,59 \% ; \mathrm{P}=3,01 \%$; Glykose $=14,75 \% ;$ Fettsäuren $37,85 \% ; \mathrm{P}: \mathrm{N}=1: 905$.

Kjeldahlbestimmung: 0,405 g Substanz verbrauchten $2,6 \mathrm{ccm}$ $\mathrm{n} /{ }_{10}-\mathrm{H}_{2} \mathrm{SO}_{4}$ à $0,0014034 \mathrm{~g} \mathrm{~N}=2,597 \% \mathrm{~N}$.

Phosphorbestimmung nach Neumann: 0,0813 g Substanz verbrauchten $4,42 \mathrm{~cm} \mathrm{n}_{/ 2}^{\prime}-\mathrm{NaHO}=3,01 \% \mathrm{P}$.

Glykosebestimmung: 0,2135 g Substanz gaben $0,0615 \mathrm{~g} \mathrm{Cu}$ $-0,0316 \mathrm{~g}$ Glykose $=14,75 \%$.

Fettsäurebestimmung: 0,2642 g Substanz gaben 0,1 g Fettsäuren $=37,85 \%$.

Dieses Präparat erwies sich ebenfalls als schwefelhaltig.

Wir sehen, daß das nach Drechsels Angaben gereinigte Jecorin im Mittel 14\% Glykose enthält, diese Prozentzahl ist unabhängig von der Anzahl der vorgenommenen Reinigungen durch Auflösen in Äther und Fällen mit Alkohol. Da ich dennoch 
glaubte, daß in Ätherlösungen des Jecorins der Äther dennoch eine Abspaltung der Glykose hervorbringen könne, wurde das Jecorin Nr. $2 \mathrm{a}$ in reinem absoluten Äther gelöst und die vollständig klare Lösung in geschlossenem Gefäß 11/2 Monate stehen gelassen. Es sammelte sich ein nur minimaler weißlicher Niederschlag, der frei war von jeglicher reduzierenden Substanz.

Die filtrierte Ätherlösung wurde durch Alkohol gefällt. Der Niederschlag getrocknet und analysiert. Die Analyse dieses Jecorins (Nr. 2b) zeigte, daß das Jecorin Nr. 2 a durch diese Operation (Stehen in Ätherlösung) sich nicht verändert hatte.

Jecorin Nr. 2b. $\mathrm{N}=2,54 \% ; \mathrm{P}=2,81 \% ;$ Glykose $=$ $14,65 \% ; \mathrm{P}: \mathrm{N}=1: 2,001$.

Kjeldahlbestimmung: 0,1985 g Substanz verbrauchten $3,6 \mathrm{ccm}$ $\mathrm{n} / 10-\mathrm{H}_{2} \mathrm{SO}_{4}$ à $0,0014028 \mathrm{~g} \mathrm{~N}=2,54 \% \mathrm{~N}$.

Phosphorbestimmung nach Neumann: 0,1673 g Substanz verbrauchten $8,5 \mathrm{ccm} n / 2-\mathrm{NaHO}=2,81 \% \mathrm{P}$.

Glykosebestimmung: 0,2965 g Substanz gaben $0,0851 \mathrm{~g} \mathrm{Cu}-$ 0,04345 g Glykose $=14,65 \%$.

Wir sehen daraus, daß im Jecorin die 14\% Glykose ziemlich fest an den lecithinarligen Komplex gebunden sind, daß dadurch die Glykose vollständig ätherlöslich wird, und daß das nach Drechsels Angaben gereinigte Jecorin eine ziemlich konstante Verbindung ist.

Die untere, dunkelbraune, sirupartige Schicht erwies sich als eine konzentrierte wässerige Lösung einer Substanz, die äußerst reich an Traubenzucker war. Diese Schicht wurde im Vakuum unter Erwärmen auf $40^{\circ}$ entwässert und nachher im Vakuumexsikkator über Schwefelsäure getrocknet. Die Entwässerung der Substanz ging sehr langsam vor sich und erforderte große Mühe. Ich bediente mich dazu des Fischerschen Vakuumapparates. Getrocknet stellte die Substanz eine gelbbraune klebrige harte Masse dar, die sich nicht pulverisieren ließ und äußerst hydroskopisch war. Sie war gänzlich unlöslich in Äther und Alkohol; in konzentrierter sirupartiger Lösung in Wasser mit Alkohol behandelt, verwandelte sie sich in große schmierige hellbraune Klumpen, die sich schmierig an die Wandungen des Gefäßes ansetzten. Diese Substanz löste sich äußerst leicht in Wasser und stellte stark verdünnt eine 
Über Jecorin und andere lecithinartige Produkte der Pferdeleber. 413

gelbe ganz durchsichtige Flüssigkeit dar. Die Analyse der trockenen Substanz gab folgende Zahlen:

$\mathrm{N}=3,66 \% ; \mathrm{P}=1,03 \% ;$ Glykose $=71,83 \% ;$ Asche $=10,23 \% ; \mathrm{P}: \mathrm{N}=1: 7,885$.

Kjeldahlb estimmung: 0,5862 g Substanz verbrauchten $15,29 \mathrm{ccm}$ $\mathrm{n} / 10-\mathrm{H}_{2} \mathrm{SO}_{4}$ à $0,0014034 \mathrm{~g} \mathrm{~N}=3,66 \% \mathrm{~N}$.

$0,3772 \mathrm{~g}$ Substanz verbrauchten $9,8 \mathrm{ccm} \mathrm{n} \mathrm{n}_{10}-\mathrm{H}_{2} \mathrm{SO}_{4}$ à $0,0014034 \mathrm{~g} \mathrm{~N}$ $=3,65 \% \mathrm{~N}$.

Phosphorbestimmung nach Neumann: 0,442 g Substanz verbrauchten $8,25 \mathrm{ccm} \mathrm{n} / 2-\mathrm{NaHO}=1,033 \% \mathrm{P}$.

0,4476 g Substanz verbrauchten $8,4 \mathrm{ccm} \mathrm{n} / \mathrm{z}-\mathrm{NaHO}=1,038 \% \mathrm{P}$.

Glykosebestimmung nach Allihn ohne vorausgehende Behandlung mit Schwefelsäure:

$0,3102 \mathrm{~g}$ Substanz gaben $0,4172 \mathrm{~g} \mathrm{Cu}$, d. i. 0,2228 g Glykose $=71,83 \%$.

Aschebestimmung: 1,3469 g Substanz gaben 0,1379 g Asche $=10,23 \%$.

Bei der weiteren Untersuchung erwies sich die Substanz als eine jecorinartige.

Durch Schmelzen der Substanz mit metallischem Natrium und Prüfung der Lösung mit Nitroprussidnatrium wurde in der Substanz die Anwesenheit von Schwefel nachgewiesen. In der wässerigen Lösung wurde durch alkoholische Chlorcadmiumlösung ein gelber Niederschlag hervorgerufen. Abweichend rom Jecorin enthielt die Substanz unter den Spaltungsprodukten keine Fettsäuren.

Jedoch gelang es mir später, wie es aus weiterem ersichtlich wird, Jecorine aus Alkoholextrakt zu bekommen, die ebenfalls keine Fettsäuren enthielten.

Aus der wässerigen Lösung der Substanz ließ sich durch Aceton ein gelblicher Niederschlag fällen, der sich sofort $\mathrm{zu}$ einer sirupartigen dunkelbraunen Masse niedersetzte. Nach einem Tage Stehens wurde die klare Lösung vom Niederschlag abgegossen, der Niederschlag mit Aceton gewaschen und getrocknet. Getrocknet ließ er sich leicht zu einem gelblichen Pulver zerreiben, das äußerst hydroskopisch war und sich an der Luft bald bräunte. Dem äußeren Aussehen nach hatte es mit Jecorin schon mehr Ähnlichkeit, als die erst beschriebene Substanz.

Hoppe-Seyler's Zeitschrift f. physiol. Chemie. LVII. 
Es enthielt, wie die Analyse zeigte: Glykose $=53,37 \%$; $\mathrm{N}=3,86 \% ; \mathrm{P}=1,53 \%$.

Glykosebestimmung: 0,6809 g Substanz gaben 0,6837 $\mathrm{g} \mathrm{Cu}$ $-0,3634$ g Substanz $=53,37 \%$.

Kjeldahlbestimmung: 0,599 Substanz gaben $16,5 \mathrm{~g} \mathrm{n} / 10-\mathrm{H}_{2} \mathrm{SO}_{4}$ à $0,0014034 \mathrm{~g} \mathrm{~N}=3,86 \% \mathrm{~N}$.

Phosphorbestimmung nach Neumann: 0,3858 g Substanz gaben $10,7 \mathrm{ccm} \mathrm{n} / \mathbf{z}-\mathrm{NaHO}=1,53 \% \mathrm{P}$.

Es ist wohl möglich, daß durch weitere Ausfällung durch Aceton der Zuckergehalt sich noch mehr vermindern würde.

Diese Substanzen haben in Anbetracht ihres hohen Glykose-, niedrigen P-Gehalts und aller ihrer Eigenschaften eine große Ähnlichkeit mit der von Mayer dargestellten Lecithinglykose.

\begin{tabular}{lc|c|c}
\hline \multicolumn{2}{c|}{$\begin{array}{c}\text { Lecithinglykose } \\
\%\end{array}$} & $\begin{array}{c}\text { Jecorinartige } \\
\text { Substanz } \\
\%\end{array}$ & $\begin{array}{c}\text { Jecorinartige Substanz } \\
\text { nach der Fällung mit Aceton } \\
\%\end{array}$ \\
\hline Glykose & 84,5 & 71,83 & 53,37 \\
P & 0,66 & 1,03 & 1,53 \\
N & 1,09 & 3,66 & 3,86 \\
\hline P : N & $1: 3,66$ & $1: 7,88$ & $1: 5,6$
\end{tabular}

Bei der von uns erhaltenen Substanz ist das Verhältnis $\mathrm{P}: \mathrm{N}$ das eine Mal $=1: 7,88$, das andere $=1: 5,6$ von demselben Verhältnis der Mayerschen Lecithinglykose $=1: 3,66$ ziemlich verschieden. Dieser Umstand wird uns aber etwas verständlicher, wenn wir uns erinnern, daß Mayer seine Lecithinglykose aus dem Lecithin darstellte, in dem das Verhältnis $\mathrm{P}: \mathrm{N}=1: 1$ war, während das Jecorin ein Verhältnis, das nahezu $1: 2$, und das Lecithin aus Alkoholextrakt der Leber ein Verhältnis, das nahezu $1: 1,7$ und größer (wie im II. Teil, Seite 455 berichtet wird, befindet sich im sekundären Alkoholextrakt ein Lecithin, dessen Verhältnis von $\mathrm{P}: \mathrm{N}=1: 2,55$ ist) zeigt.

Hierbei möchte ich noch folgendes erwähnen. Beim Vergleichen der Analysenzahlen der Lecithinglykose mit den Analysenzahlen des Lecithins und der Glykose, die bei uns auf der Seite 400 angeführt waren, kommt Mayer zu der Meinung, 
daß bei der Vereinigung von Traubenzucker und Lecithin ein phosphorartiger Komplex aus letzterem ausgetreten sei. Doch sei, sagt Mayer, die Entscheidung dieser Frage jetzt noch unmöglich, da sie dazu einer größeren Reihe von Analysen bedürfe.

Man kann jedoch die Frage auch anders stellen. Wenn man in Betracht zieht, daß Mayers Lecithinglykose ca. 85\% Glykose enthält, und annimmt, daß hier eine einfache Mischung von 85 Gewichtsteilen Glykose und 15 Gewichtsteilen Lecithin vorliege, so müßte die theoretisch gedachte Verbindung $43,75 \% \mathrm{C}$, $7,31 \% \mathrm{H}, 0,27 \% \mathrm{~N}, 0,585 \% \mathrm{P}, 48,18 \% 0$ enthalten. Statt dessen erhielt Mayer eine Verbindung von 38,7\% C, 9,29\% $\mathrm{H}$, $1,09 \% \mathrm{~N}, 0,60 \% \mathrm{P}, 50 \% 0$. Wir sehen hieraus, daß die P-Mengen in beiden Fällen ziemlich nahe übereinstimmen, und daß im Gegenteil der N-Gehalt in der Lecithinglykose bedeutend höher ist, als in der theoretisch gedachten Verbindung; der C-Gehalt indes kleiner, kleiner sogar, als der der Glykose. Man kann daraus schließen, daß hier keine einfache Mischung vorliege, sondern vielmehr eine Wechselwirkung zwischen den Bestandteilen des Lecithins und der Glykose. Die Verringerung des C-Gehaltes könnte von dem Wegfallen der Fettsäuren herstammęn. Wir sahen, daß bei der von mir dargestellten jecorinähnlichen sirupartigen Substanz die Fettsäuren ganz fehlten. Das Jecorin Nr. 1 enthielt, bei 14,4\% Glykose 40,75\% Fettsäuren, ein zweites Jecorin Nr. 2, bei 14,75\% Glykose, $37,85 \%$ Fettsäuren, d. h. beim Hinzutreten von nur $14 \%$ Glykose hatte sich die Fettsäuremenge mehr als um ein Drittel verkleinert (Lecithin Nr. 2 enthielt 63,65\% Fettsäuren, der Theorie nach enthielt das Distearyllecithin $=70,47 \%$; Dipalmytolecithin $=68,25 \%$; Dioleolecithin $=70,31 \%$ ).

Freilich darf auf Grund der wenigen Analysen keine Behauptung aufgestellt werden und die Lösung der Frage bedarf weiterer zahlreicher Analysen.

Ich habe ebenfalls Lecithinglykose aus Lecithin $\mathrm{Nr} .2$ und Glykose nach Mayers Vorschrift darzustellen gesucht. Es wurden 2 Gewichtsteile des Lecithin $\mathrm{Nr}$. 2 mit 5 Gewichtsteilen Glykose in Alkohollösungen vereinigt, verdunstet, der Rückstand in wasserhaltigem Äther gelöst, filtriert und 
mit Alkohol gefällt. Es entstand eine dunkelbraune sirupartige Fällung, die mit der aus der Pferdeleber bei diesem Versuch dargestellten jecorinähnlichen sirupartigen Substanz große Ähnlichkeit hatte.

Diese Lecithinglykose war, abweichend von Mayer, in Äther nur wenig löslich, löste sich dagegen vollständig klar in Wasser. Die Ätherlösung gab wiederum eine Fällung durch Alkohol, jedoch war die Fällung eine geringe, so daß die Lecithinglykose sich nicht nach der von Drechsel für das Jecorin angegebenen Methode reinigen ließ. Diese Lecithinglykose habe ich bis dahin noch nicht analysiert.

\section{Versuch III.}

In dem vorhergehenden Versuche stellte nach dem Auflösen des Rückstandes des Alkoholextraktes in Äther die untere Schicht eine Lösung der jecorinähnlichen Substanz in Wasser dar. Da ich vermuten konnte, daß diese Substanz dank der Anwesenheit von Wasser in der Leber in den Alkoholextrakt übergegangen sei, wurde in diesem dritten Versuche die Extraktion der Leber unter Wasserausschluß vorgenommen. Hierbei wollte ich einen Aufschluß darüber erhalten, ob man bei Wasserausschluß dieselben Produkte erhalte, wie bei den ersten Versuchen, eventuell ob die Anwesenheit von Wasser beim Extrahieren der Leber auf die Darstellung von Jecorin einen Einfluß ausübe. Die Trocknung der Substanz wurde nach der von Erlandsen ${ }^{1}$ ) vorgeschlagenen Methode vorgenommen.

$\mathrm{Zu}$ diesem $\mathrm{Zwecke}$ wurde die Pferdeleber mit einer Fleischhackmaschine fein zerteilt, worauf die Masse in dünnen Schichten auf Platten ausgebreitet wurde. Die Trocknung wurde mittels eines durch Ventilationsmotor erzeugten kräftigen Luftstroms unter leichter Erwärmung hervorgerufen. Nach 12 Stunden hatte das Material fast seinen ganzen Wassergehalt verloren. Darauf wurden die festen Kuchen in kleinere Stücke zerschnitten und im Vakuumexsikkator über Schwefelsäure stehen gelassen. Nach 1-2 Tagen konnte man das Präparat zu einem feinen

1) A. Erlandsen, Diese Zeitschrift, Bd. LI, Heft 1 u. 2, S. 83. 
Pulver mittels einer Handmühle verreiben, und das Pulver wurde weiter im Vakuumexsikkator getrocknet. Derart getrocknet verlor das Material 70\% Wasser.

Das so erhaltene Pulver wurde mit absolutem Alkohol übergossen. Nach einigen Tagen wurde die Alkohollösung, die hellgelb gefärbt war, abgegossen, filtriert und in vacuo bis zur Trockene abgedampft. Der Rückstand wurde mit Äther durchgeschüttelt, worin er sich mit Hinterlassen eines schmierigen gelblichen Niederschlages von derselben Natur, wie beim zweiten Versuch, löste. Dieser Niederschlag wurde beim Stehen an der Luft zähe und nahm eine gelblich braune Farbe an. Beim Stehen der ätherischen Lösung schied sich aus ihr keine sirupartige Schicht aus. Die Ätherlösung wurde abfiltriert und mit Alkohol gefällt. Es bildete sich eine nur geringe Masse dunkelbraunen klebrigen Niederschlages. Dieser Niederschlag wurde abfiltriert und mit Äther behandelt; es löste sich in ihm nur ein kleiner Teil des Niederschlages. Der Hauptteil war in Äther unlöslich, löste sich aber klar in Wasser; die wässerige Lösung reduzierte die Fehlingsche Lösung kaum.

Aus diesem Versuche ersehen wir, daß beim Extrahieren der entwässerten Leber mit absolutem Alkohol keine Glykose in Lösung übergegangen ist; es fehlte die obenbeschriebene sirupartige Schicht und die Ausbeute des Jecorins war nur minimal.

Zur Darstellung des Jecorins ist also die Anwesenheit von Wasser in Extraktionsmitteln notwendig.

\section{Versuch IV.}

Da im vorhergehenden Versuche beim Extrahieren der Leber mit absolutem Alkohol die Ausbeute an Jecorin sehr gering war, so wurde bei diesem Versuche die nach oben beschriebener Methode getrocknete Pferdeleber mit 95\% igem Alkohol behandelt. Das Alkoholextrakt wurde in 2 Teile geteilt; der eine Teil bis zur Trockene, der andere bis zur Sirupkonsistenz abgedampft. Der bis zur Trockene abgedampfte Teil wurde zur Darstellung des Jecorins streng nach der Drechs elschen Methode bearbeitet. Der Abdampfungsrückstand wurde mit Alkohol durch- 
geschüttelt, bis dieser sich nicht mehr färbte. Es blieben grobe gelblichweiße Flocken nach, die in Äther gelöst wurden.

Dabei blieb ein gewisser Teil ungelöst in Äther, er löste sich leicht in Wasser und reduzierte die Fehlingsche Lösung. $\mathrm{Da}$ dieser ätherunlösliche Teil $\mathrm{P}, \mathrm{N}$ und $\mathrm{S}$ enthielt, so muß er als eine jecorinähnliche Substanz angesehen werden, wenigstens dieselbe enthalten.

Die ätherische Lösung wurde in einem hohen Zylinder stehen gelassen, wobei sich ein bedeutender weißlicher Niederschlag bildete. Die klare ätherische Lösung wurde abfiltriert, etwas eingeengt und mit absolutem Alkohol gefällt. Es entstand ein gelblichweißer Niederschlag, der stellenweise mit einer braunen Substanz vermischt war. Am nächsten Tage wurde dieser Niederschlag abfiltriert. Er erwies sich als unlöslich in absolutem Äther, löste sich aber in demselben, nachdem einige Tropfen Wasser hinzugefügt wurden. Die ätherische Lösung wurde abermals mit Alkohol gefällt und diese Operation noch 3 mal wiederholt. Man erhielt zuletzt einen fast weißen Niederschlag, der sich erst nach dem Stehen absetzte; die alkoholisch ätherische Mutterlauge war farblos. Der Niederschlag wurde abfiltriert und stellte getrocknet und zerrieben ein fast weißes Pulver dar. Das so dargestellte Jecorin (Jecorin Nr. 3 a) enthielt $\mathrm{P}=2,83 \% ; \mathrm{N}=2,53 \%$; Glykose $=14,13 \% ; \mathrm{P}: \mathrm{N}=1: 2$.

Phosphorbestimmung nach Neumann: 0,1465 g Substanz verbrauchten $7,5 \mathrm{ccm} \mathrm{n} / \mathrm{s}$-Natronlauge $=2,833 \% \mathrm{P}$.

Kjeldahlbestimmung: $0,1664 \mathrm{~g}$ Substanz verbrauchten $3,02 \mathrm{ccm}$ $\mathrm{n} / 10-\mathrm{H}_{2} \mathrm{SO}_{4}$ à $0,0014034 \mathrm{~g} \mathrm{~N}=2,547 \% \mathrm{~N}$.

Glykosebestimmung: 0,1558 g Substanz gaben 0,0422 $\mathrm{g} \mathrm{Cu}$ $-0,02201 \mathrm{~g}$ Glykose $=14,13 \%$.

Der andere Teil des Alkoholextraktes, der nur bis zur Sirupkonsistenz eingedampft war, wurde direkt in Äther gelöst. Beim Stehen setzten sich am Boden des Gefäßes unbedeutende Mengen von der sirupartigen jecorinähnlichen Substanz ab, und es blieb ungelöst ein gelblicher Niederschlag von derselben Natur, wie in Versuch Nr. 2. Die ätherische Lösung wurde eingeengt, mit Alkohol gefällt und bei weiterem ebenso behandelt, wie bei der Darstellung des Jecorins Nr. 3 a. 
Über Jecorin und andere lecithinartige Produkte der Pferdeleber. 419

Das so erhalten Jecorine Nr. $3 \mathrm{~b}$ zeigte eben dieselben Zahlen für $\mathrm{P}, \mathrm{N}$ und Glykose, wie das Jecorin $\mathrm{Nr}$. 3a.

$\mathrm{P}=2,87 \% ; \mathrm{N}=2,57 \% ;$ Glykose $=14,61 \%$.

Phosphorbestimmung nach Neumann: 0,2014 g Substanz verbrauchten $10,45 \mathrm{ccm} \mathrm{n} / 2-\mathrm{NaHO}=2,87 \% \mathrm{P}$.

Kjeldahlbestimmung: 0,243 $\mathrm{g}$ Substanz verbrauchten $4,45 \mathrm{ccm}$ $\mathrm{n} / 10-\mathrm{H}_{2} \mathrm{SO}_{4}$ à $0,0014034 \mathrm{~g} \mathrm{~N}=2,57 \% \mathrm{~N}$.

Glykosebestimmung: 0,2371 $\mathrm{g}$ Substanz gaben $0,0677 \mathrm{~g} \mathrm{Cu}$ $-0,03465 \mathrm{~g}$ Glykose $=14,61 \%$.

Aus diesem Versuche sehen wir, daß ein schon geringer Wassergehalt in dem zum Extrahieren benutzten Alkohol (5\%) genügend ist, um die Darstellung von Jecorin zu ermöglichen, und daß die Behandlung des bis zur Trockene abgedampften Alkoholextraktes mit absolutem Alkohol zur Entfernung des Lecithins (wie es Drechsel tat) überflüssig sei, da man zu denselben Resultaten kommt, auch wenn man die Darstellungsmethode des Jecorins $\mathrm{Nr} .2 \mathrm{~b}$ angewendet wird. Es eignet sich also zur Darstellung des Jecorins besser die Darstellungsmethode des Jecorins $\mathrm{Nr}$. $3 \mathrm{~b}$ und die im Versuche II angewandte Methode.

\section{Versuch Nr. V.}

Die entwässerte, zu Pulver zerriebene Pferdeleber wurde mit 85\% igem Alkohol begossen und einige Tage im Thermostaten bei $37^{\circ}$ stehen gelassen. Das Alkoholextrakt wurde abfiltriert und zur Trockne abgedampft. Der Rückstand mit Äther behandelt und die ätherische Lösung durch Alkohol gefällt.

Eine kleine Probe der ätherischen Lösung wurde abgedampft, der Rückstand getrocknet und analysiert. Er enthielt $2,03 \% \mathrm{P}, 4,07 \% \mathrm{~N}$ und $0,789 \%$ Glykose. Der geringe Glykosegehalt zeigt an, daß hier der gesamte Traubenzucker wahrscheinlich an Jecorin gebunden ist.

In der ätherischen Lösung wurde durch Zusatz von Alkohol ein Niederschlag erzeugt, der teilweise sirupartig war, teilweise aus gelblichweißen Flocken bestand.

Einzelne Versuche haben bestätigt, daß dieser Niederschlag sich in Äther nur unvollkommen löste, wobei ein bedeutender Teil in Form von gelblichen Flocken unlöslich blieb. 
Dieser in Äther unlösliche Teil löste sich leicht in Wasser und reduzierte stark die Fehlingsche Lösung. Er enthielt auch N, P und S. Es war also eine in Äther unlösliche jecorinartige Substanz, von welcher schon früher die Rede war.

Der oben beschriebene, in ätherischer Lösung durch Alkohol hervorgerufene Niederschlag wurde abfiltriert, durch Alkohol gewaschen und im Vakuumexsikkator getrocknet. Das so ohne Reinigung durch wiederholtes Auflösen in Äther und Umfällen mit Alkohol erhaltene rohe Jecorin enthielt $\mathrm{P}=$ $2,24 \%, \mathrm{~N}=5,80 \%$, Glykose $=19,32 \%$.

Kjeldahlbestimmung: 0,1608 g Substanz verbrauchten $6,73 \mathrm{ccm}$ $\mathrm{n} / 10-\mathrm{H}_{2} \mathrm{SO}_{4}$ à $0,00189714 \mathrm{~g} \mathrm{~N}=5,852 \mathrm{~N}$.

$0,258 \mathrm{~g}$ Substanz verbrauchten $10,65 \mathrm{ccm} \mathrm{n} / 10-\mathrm{H}_{2} \mathrm{SO}_{4}=5,71 \% \mathrm{~N}$.

Phosphorbestimmung nach Woy: 0,271 g Substanz gaben $0,3536 \mathrm{~g} \mathrm{MoO}_{3} \mathrm{P}_{2} \mathrm{O}_{5}=2,24 \% \mathrm{P}$.

Glykosebestimmung: 0,3652 g Substanz gaben $0,118 \mathrm{~g}$ Cu d. i. $-0,07088 \mathrm{~g}$ Glykose $=10,32 \%$.

Ein zweites Präparat von Rohjecorin, aus einer anderen Pferdeleber stammend, wurde in derselben Weise dargestellt (indem der nach der ersten Ausfällung durch Alkohol aus Ätherlösung gebildete Niederschlag abfiltriert und darauf getrocknet wurde). Dasselbe enthielt: $\mathrm{P}=2,66 \%, \mathrm{~N}=4,05 \%$, Glykose $=14,96 \%$.

Kjeldahlbestimmung: $0,4894 \mathrm{~g}$ Substanz verbrauchten $14,07 \mathrm{ccm}$ $\mathrm{n} / 10-\mathrm{H}_{2} \mathrm{SO}_{4}$ à $0,0014034 \mathrm{~g} \mathrm{~N}=4,03 \% \mathrm{~N}$.

$0,263 \mathrm{~g}$ Substanz verbrauchten $7,65 \mathrm{ccm} \mathrm{n} / 10-\mathrm{H}_{\mathrm{g}} \mathrm{SO}_{4}=4,03 \mathrm{~g} \mathrm{~N}$.

Phosphorbestimmung nach Neumann: 0,4496 g Substanz verbrauchten $21,29 \mathrm{ccm} \mathrm{n} / 2$-Natronlauge $=2,62 \% \mathrm{P}$.

0,2885 g Substanz gaben $14,12 \mathrm{ccm} \mathrm{n} / \mathrm{z}-$ Natronlauge $-2,71 \% \mathrm{P}$.

Glykosebestimmung nach Allihn: 0,4597 g Substanz gaben $0,135 \mathrm{~g} \mathrm{Cu}-0,0688 \mathrm{~g}$ Glykose $=14,96 \%$.

Das so dargestellte, in vacuo getrocknete, rohe Jecorin war weder in Alkohol, noch in Äther löslich und löste sich nur langsam in Wasser zu einer trüben, gelbbraunen Flüssigkeit. Da ich jedoch bemerkte, daß dieses Jecorin beim Stehen sich dennoch etwas in wasserhaltigem Äther löste, so wurde das trockene Jecorin im Soxhletapparat mit Ätherdämpfen extrahiert. Dabei blieb in der Hülse ein ätherunlöslicher Rückstand. Er war in Alkohol ebenfalls unlöslich, löste sich 
jedoch in Wasser. Es war wiederum die jecorinähnliche, in Äther unlösliche Substanz, der wir schon zweimal begegnet waren. Sie bleibt bei der Reinigung des rohen Jecorinniederschlages durch mehrfaches Auflösen in Äther und Ausfällung durch Alkohol nach Drechselschen Angaben jedesmal als ein in Äther unlöslicher Rückstand zurück und wurde von den Autoren außer acht gelassen.

Die Substanz enthielt: $\mathrm{N}=4,43 \% ; \mathrm{P}=2,923 \%$; Glykose $=18,01 \% ; \mathrm{P}: \mathrm{N}=1: 3,36$.

Kjeldahlbestimmung: 0,1964 g Substanz verbrauchten $6,2 \mathrm{ccm}$ $\mathrm{n} / 10-\mathrm{H}_{2} \mathrm{SO}_{4}$ à $0,0014034 \mathrm{~g} \mathrm{~N}=4,43 \% \mathrm{~N}$.

Phosphorbestimmung nach Neumann: 0,171 g Substanz verbrauchten $9,05 \mathrm{ccm} \mathrm{n} / 2-\mathrm{Natronlauge}=2,923 \% \mathrm{P}$.

Glykosebestimmung: 0,2461 g Substanz gaben 0,0869 g Cu $-0,0443 \mathrm{~g}$ Glykose $=18,01 \%$ Glykose.

Betrachten wir diese Analysenzahlen, so müssen wir die Substanz als eine Art Jecorin anerkennen. Sie unterscheidet sich von den durch Ausfällen aus Äther mit Alkohol nach Drechselschen Angaben gereinigten Jecorinen durch den fast doppelten Gehalt an N und etwas höheren Gehalt an Glykose. Sie enthält höhere Fettsäuren wie das Jecorin. Bei der Reinigung des Jecorins durch Ausfällen mit Alkohol wird also diese jecorinähnliche Substanz dem Endprodukte - reines Jecorin entzogen.

Die beim Extrahieren des rohen Jecorins im Soxhletapparat erhaltene ätherische Jecorinlösung wurde durch Alkohol gefällt, der Niederschlag in Äther gelöst usw. Nach der dritten Ausfällung löste sich der Niederschlag vollständig klar in Äther und wurde quantitativ durch Alkohol gefällt. Er enthielt (Jecorin Nr. IV): $\mathrm{N}=2,52 \%, \mathrm{P}=2,89 \%$, Glykose $=$ $14,51 \%, P: N=1: 1,93$; das Jecorin enthielt höhere Fettsäuren und Schwefel.

Kjeldahlbestimmung: 0,3152 g Substanz verbrauchten $4,95 \mathrm{ccm}$ $\mathrm{n} / 10-\mathrm{H}_{2} \mathrm{SO}_{4}$ à $0,0014034 \mathrm{~g} \mathrm{~N}=2,52 \% \mathrm{~N}$.

Phosphorbestimmung nach Neumann: 0,064 g Substanz verbrauchten $3,35 \mathrm{ccm} \mathrm{n} / 2-\mathrm{Natronlauge}=2,898 \% \mathrm{P}$. Glykosebestimmung: $9,1993 \mathrm{~g}$ Subs 14 gaben $0,054 \mathrm{~g} \mathrm{Cu}$
$-0,0279 \mathrm{~g}$ Glykose $=14,51 \%$. 


\section{Versuch Nr. VI.}

Zum Schluß sei hier noch erwähnt, daß es mir gelungen ist, ein Jecorinpräparat darzustellen, das frei von Glykose war oder nur Spuren von Glykose enthielt, jedoch nach einer anderen Darstellungsmethode, als die Drechselsche.

Die vollständig getrocknete und zu Pulver zerriebene Pferdeleber wurde mit absolutem Alkohol extrahiert. Das Filtrat wurde bis zur Trockene abgedampft und der Rückstand mit absolutem Alkohol behandelt. Dabei blieb ungelöst ein gelblichbrauner Rückstand, von dem die Lösung abfiltriert wurde. Die Lösung wurde in einen Scheidetrichter gegossen, es bildeten sich 2 Schichten. Die obere, gelbliche Schicht enthielt das Lecithin, die untere war gelblichbraun und dicht. Nach dem Stehen bildete sich in der unteren Schicht eine Art dünner, nadelförmiger Krystalle, von denen die ganze Schicht durchdrungen war. Die untere Schicht wurde abgezapft und mit absolutem Alkohol durchgeschüttelt; der größte Teil dieser Schicht löste sich in Alkohol mit gelber Farbe und eine braune Substanz klebriger Natur blieb ungelöst. Die Krystalle waren dabei verschwunden. Diese braune Substanz, die nur einen geringen Teil der unteren Schicht bildete, wurde mit Alkohol erschöpft, bis der letztere sich nicht mehr färbte, und darauf in Äther gelöst und durch Alkohol gefällt. Der Niederschlag in vacuo getrocknet. Getrocknet ließ er sich zu einem gelblichen Pulver zerreiben. Er enthielt $S$ und zeigte alle Eigenschaften des Jecorins, jedoch reduzierte er Fehlingsche Lösung nicht. Jedoch ließ sich auf solche Weise eine nur geringe Menge von Jecorin darstellen; der Grund dazu liegt darin, daß in diesem Falle die Leber im getrockneten Zustande mit absolutem Alkohol extrahiert wurde (siehe Versuch Nr. III).

Die Analyse der Substanz zeigte: $\mathrm{P}=3,48 \% ; \mathrm{N}=$ $2,45 \%$; Glykose fehlt; Asche $=10,35 \% ; \mathrm{Na}=1,12 \%$; $\mathrm{P}: \mathrm{N}=1: 1,6$.

Phosphorbestimmung nach Woy: 0,1617 g Substanz gaben $0,3266 \mathrm{~g} \mathrm{MoO}_{3} \mathrm{P}_{2} \mathrm{O}_{5}=3,48 \% \mathrm{P}$.

$0,1973 \mathrm{~g}$ Substanz gaben $0,3996 \mathrm{~g} \mathrm{MoO}_{3} \mathrm{P}_{8} \mathrm{O}_{5}=3,49 \% \mathrm{P}$. 
Kjeldahlbestimmung: $0,1552 \mathrm{~g}$ Substanz gaben $2,7 \mathrm{ccm}$ n/10$\mathrm{H}_{2} \mathrm{SO}_{4}$ à $0,000139714 \mathrm{~g} \mathrm{~N}=2,43 \% \mathrm{~N}$.

$0,1794 \mathrm{~g}$ Substanz gaben $3,18 \mathrm{ccm} \mathrm{n}_{1 / 10}-\mathrm{H}_{8} \mathrm{SO}_{4}=2,47 \% \mathrm{~N}$.

Aschebestimmung: $0,4878 \mathrm{~g}$ Substanz gaben $0,0505 \mathrm{~g}$ Asche $=10,35 \%$.

$\mathrm{Na}$-Bestimmung: $0,4878 \mathrm{~g}$ Substanz gaben $0,0168 \mathrm{~g} \mathrm{Na} \mathrm{NO}_{4}$ $0,0054432 \mathrm{~g} \mathrm{Na}=1,12 \% \mathrm{Na}$.

Wenn wir die $2,45 \% \mathrm{P}$ auf $\mathrm{HPO}_{3}$ umrechnen, so bekommen wir $8,97 \% \mathrm{HPO}_{3}$.

Fügen wir zu dieser Zahl den Na-Gehalt, so bekommen wir:

$$
\begin{array}{ll}
\mathrm{HPO} & =8,97 \% \\
\mathrm{Na} & =1,12 \% \\
& \text { Summa } . \quad 10,09 \% \text {, eine Zahl, die dem }
\end{array}
$$

Aschegehalt $(10,35 \%)$ sehr nahe ist.

Die $\mathrm{N}$ - und P-Zahlen, sowie das Verhältnis $\mathrm{P}: \mathrm{N}$ und in diesem Jecorin ist denen der Lecithine Nr. I und II ziemlich nahe.

\section{Teil.}

Während meiner Untersuchungen über das Jecorin erschien die gründliche Arbeit von A. Erlandsen:1) «Untersuchungen über die lecithinartigen Substanzen des Myocardiums und der quergestreiften Muskeln». Die früheren Autoren, die sich mit Lecithin beschäftigten, haben dasselbe aus dem Alkoholextrakt verschiedener Organe dargestellt. Die von ihnen erhaltenen Lecithine zeigten einen ziemlich verschiedenen $\mathrm{P}$ - und N-Gehalt, wobei auch das Verhältnis $P: N$ bedeutend von dem des theoretisch gedachten Lecithins, das gleich $1: 1$ sein sollte, abwich.

Thudichum ${ }^{2}$ ) hat festgestellt, daß außer dem Lecithin, bei dem das Verhältnis $P: N$ gleich $1: 1$ ist, andere lecithinartige Produkte, denen er den gemeinschaftlichen Namen «Phosphatide» gegeben hatte, existieren, in denen das Verhältnis zwischen $\mathrm{N}: \mathrm{P}$ ein anderes einfaches Verhältnis ist $(\mathrm{N}: \mathrm{P}=2: 1$, $\mathrm{N}: \mathrm{P}=2: 2$ ).

Zur Trennung und Isolierung der verschiedenen Phosphatide schlägt Erlandsen folgende Methode vor: Das behutsam getrocknete und pulverisierte Organ wird einer primären vollständigen Ätherextraktion und

1) Erlandsen, Diese Zeitschrift, Bd. XXXI, Heft 1.

2) Thudichum, Die chemische Konstitution des Gehirns der Menschen und Tiere, 1901. 
einer sekundären vollständigen Alkoholextraktion unterworfen. Bei einem solchen Verfahren werden im Ätherextrakt und im Alkoholextrakt Phosphatide gefunden, die ein verschiedenes Verhältnis N : P aufweisen. Es gelang nämlich Erlandsen, aus dem Ätherextrakt des Myocardiums und der quergestreiften Muskeln Phosphatide zu isolieren, die ein Verhältnis $\mathrm{N}: \mathrm{P}=1: 1$ und $\mathrm{N}: \mathrm{P}=1: 2$ aufweisen, im Alkoholextrakt dagegen wird ein Posphatid gefunden, dessen Verhältnis $\mathrm{P}: \mathrm{N}=1: 2$ ist.

Auf Grund der verschiedenen Verhältnisse $\mathrm{N}: \mathrm{P}$ schlägt Erlands en folgende Einteilung der Phosphatide vor:

1. Monoamido-monophosphatide $\mathrm{N}: \mathrm{P}=1: 1$

2. Monoamido-diphosphatide $\quad \mathrm{N}: \mathrm{P}=1: 2$

3. Diamido-monophosphatide $\mathrm{N}: \mathrm{P}=2: 1$

4. Diamido-diphosphatide $\quad \mathrm{N}: \mathrm{P}=\mathrm{2}: 2$

Die Verarbeitung des Ätherextraktes wurde von Erlandsen auf folgende Weise durchgeführt.

Der filtrierte Ätherextrakt des getrockneten Organs wird in vacuo abgedampft, die restierende braungelbe sirupartige Masse mit einer geringen Menge reinen Äthers behandelt, wodurch die Hauptmenge a.ufgelöst wird, und leicht von einem unbedeutenden weißlichen Rest (Fraktion a) abfiltriert. Diese Fraktion a hinterließ beim Erhitzen auf Platinblech einen bedeutenden unverbrennbaren Rest, welcher Cl- und P-Reaktion gibt. Bei quantitativen P- und N-Bestimmungen wurden $6,39 \% \mathrm{P}$ und $1,86 \% \mathrm{~N}$ gefunden. Daraus schließt Erlandsen, daß a zum großen Teil aus unorganischen Stoffen (Salzen) besteht. Der von a abfiltrierten ätherischen Lösung wird kaltes wasserfreies Aceton zugesetzt, so lange noch ein Niederschlag entsteht. Der Acetonniederschlag besteht teilweise aus einer größeren, braungelben zusammenballenden Masse, teilweise aus einem freien weißlichen Niederschlag.

Der Acetonniederschlag wird in absolutem Äther gelöst und mit 4 Volumen absoluten Alkohols gefällt. Der gebildete Niederschlag (b), der teilweise aus gelbbraunen, klebrigen Massen, teilweise aus einem losen weißlichen Niederschlag besteht, wird abfiltriert und mit kaltem Alkohol gowaschon. Das athoralkoholisolic Filtrat vom Niodorsohlage b wird abgedampft und in absolutem Alkohol gelöst, wobei ein geringer unlöslicher Teil desselben Charakters wie $\mathrm{b}$ restiert, den man diesem beifügt.

Demnach sind die acetonunlöslichen Bestandteile des Ätherextraktes in einen alkohollöslichen Teil $\mathrm{C}$ und einen alkoholunlöslichen Teil b getrennt.

Der Niederschlag b wird weiter bei $60^{\circ}$ mit absolutem Alkohol behandelt, wodurch sich der weißliche lose Niederschlag auflöst, während die bräunlichen Massen, die in der Wärme etwas sirupartig sind, beim Abgießen der Alkohollösung zurückbleiben.

Das schwach gelbliche alkoholische Filtrat scheidet bei der Abkühlung einen losen weißen Niederschlag (b a) aus. 
Die ungelöste gelbbraune Substanz (b 1 ) wird in Äther aufgelöst und mit Aceton gefällt; der Niederschlag von Aceton befreit und durch Umfällung aus warmem Essigester gereinigt.

Das alkoholische Filtrat von b wird in vacuo abgedampft, in Äther gelöst und durch Aceton gefällt. Der Niederschlag bildet helle orangefarbene Massen, welche das Lecithin (C) darstellen. Zur Übersicht sei hier das von Erlandsen für die Trennung angegebene Schema angeführt.

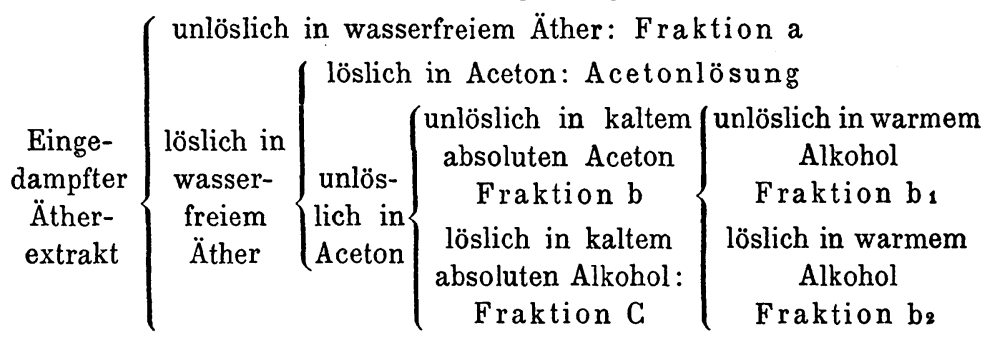

Die Acetonlösung enthält Fette und Spuren von Phosphatiden. Die Fraktion $b_{2}$ scheint wesentlich aus fettartigen Stoffen $z u$ bestehen.

Die Hauptprodukte des Ätherextraktes sind die Fraktionen b 1 und C.

Aus der Fraktion $b_{1}$ hat Erlandsen ein Phosphatid dargestellt, dem er den Namen Cuorin gegeben hat.

Das Cuorin ist eine gelbbraune Substanz, die nach dem Trocknen von harter, fast harziger Konsistenz ist und sich einigermaßen leicht pulverisieren läßt. Sie ist sehr hygroskopisch und wird bei Aufnahme von Wasser klebrig, später flüssig. Sie gibt deutliche N-Reaktion und keine Reaktion auf Schwefel. Sie reduziert Fehling sche Lösung nicht, selbst nicht nach längerem Kochen mit verdünnter Schwefelsäure. In Wasser schwillt das Cuorin zu einer trüben emulsionartigen Lösung auf, beim Zusatz von Alkalien wird die Lösung klar.

Die Analyse des Cuorins gab im Durchschnitt folgende Zahlen: $\mathrm{C}=61,63 \% ; \mathrm{H}=9,09 \% ; \mathrm{N}=1,015 \% ; \mathrm{P}=4,46 \% ; \mathrm{O}=23,80 \%$; $\mathrm{N}: \mathrm{P}=1: 1,99$.

Daraus berechnet Erlandsen für das Cuorin die Formel

$$
\mathrm{C}_{71} \mathrm{H}_{125} \mathrm{NP}_{2} \mathrm{O}_{21} \text {. }
$$

Das Verhältnis $\mathrm{N}: \mathrm{P}$ ist nahe $1: 2$, das Cuorin ist also ein Monoamido-Diphosphatid. Die Jodzahl des frisch hergestellten Cuorins beträgt ca. 101, während Jodzahlbestimmungen längere Zeit auf bewahrter oxydierter Präparaten nur ca. 22 gaben. Durch Analysen von frischen und lange gestandenen Präparaten wurde nachgewiesen, daß Cuorin zu den sehr leicht autoxydablen Substanzen gehört.

Aus der Fraktion G stellte Erlandsen auf oben beschriebenem Wege ein Lecithin dar, welches bei der Analyse folgende Resultate gab.

$\mathrm{C}=66,19-66,42 \% ; \mathrm{H}=10,08-10,24 \% ; \mathrm{N}=1,84-1,90 \%$; $\mathrm{P}=3,87-4,03 \% ; 0=(17,71) ; \mathrm{P}: \mathrm{N}=1: 1,05$. 
Daraus berechnet Erlandsen die Formel $\mathrm{C}_{43} \mathrm{H}_{80} \mathrm{NPO}_{9}$. Das Lecithin ist somit ein Mono-amido-mono-phosphatid und stimmt seiner Zusammensetzung nach mit dem theoretisch gedachten Lecithin überein, das bekanntlich eine Esterverbindung von 1 Mol. Glycerin mit 2 Mol. höheren Fettsäuren und $1 \mathrm{Mol}$. Phosphorsäure, die mit $1 \mathrm{Mol}$. Cholin verbunden ist, sein soll. Ein ähnliches Lecithin ist im Hühnereidotter vorgefunden.

Der sekundäre Alkoholextrakt wurde von Erlandsen auf folgende Weise verarbeitet. Die Lösung wurde abgedampft, der Rückstand in geringer Menge absoluten Alkohols gelöst. Die Lösung vom ungelöst gebliebenen Teil $(\alpha)$ abfiltriert und wiederum in vacuo abgedampft. Der Rückstand wird mit Äther übergossen, worin er sich, eine weißliche Sub$\operatorname{stanz}(\beta)$ hinterlassend, löst. Die Ätherlösung wird eingeengt und mit Aceton gefällt und der Acetonniederschlag in wenig Alkohol gelöst. Setzt man zur alkoholischen Lösung absoluten Alkohol, so entsteht ein weißgelber klebriger Niederschlag $(r)$. Das alkoholische Filtrat enthält die Hauptmenge der Phosphatide des Alkoholextraktes (Fraktion $\delta$ ).

Zur Übersicht gibt Erlandsen folgendes Schema:

\begin{tabular}{|c|c|c|c|c|}
\hline \multirow[b]{2}{*}{$\begin{array}{c}\text { Alkohol- } \\
\text { extrakt }\end{array}$} & \multicolumn{4}{|c|}{$\begin{array}{l}\text { unlöslich in absolutem Alkohol }(\alpha) \\
\qquad \begin{array}{c}\text { unlöslich in absolutem Äther }(\beta) \\
\text { Acetonlösung }\end{array}\end{array}$} \\
\hline & $\left\{\begin{array}{c}\text { löslich in } \\
\text { absolutem } \\
\text { Alkohol }\end{array}\right.$ & $\begin{array}{l}\text { löslich in } \\
\text { absolutem } \\
\text { Äther }\end{array}$ & $\begin{array}{l}\text { Aceton- } \\
\text { fällung }\end{array}$ & $\left\{\begin{array}{l}\text { der in der konzentrierten } \\
\text { alhoholischen Lösung des } \\
\text { Acetonniederschlages mit } \\
\text { absolutem Alkohol hervor- } \\
\text { gerufene Niederschlag ( }() \text {. } \\
\text { Filtrat nach Ausfällung } \\
\text { von } \curlyvee(১) \text {. }\end{array}\right.$ \\
\hline
\end{tabular}

Die Fraktion $\alpha$ besteht seiner Hauptmenge nach aus unorganischen Stoffen und enthält keine reduzierende Substanzen.

Die Fraktion $\beta$ ist in Äther unlöslich, schwer in absolutem Alkohol, dagegen leicht und klar in Wasser. Die Lösung in verdünntem Alkohol wird von der alkoholischen Chlorcadmiumlösung gefällt. Die Substanz enthielt Schwefel und keine reduzierende Substanzen und nur $2-3 \%$ Fettsäuren. Sie gab bei der Analyse 0,2\% P und 6,82\% N. Erlandsen glaubt in dieser Substanz, die einen ziemlich bedeutenden Teil des Alkoholextraktes bildet, viel Gemeinsames mit der «Phosphorfleischsäure (Siegfrieds ${ }^{1}$ ) Muskelnucleon) zu erblicken.

Die Fraktion $r$ hatte große Ähnlichkeit mit dem Jecorin. Sie zeigte viele dem Jecorin eigentümliche Reaktionen und reduzierte deutlich die Fehlingsche Lösung. Die Substanz enthielt 3,47\% P und 1,70\% N und zeigte Schwefelreaktion.

1) Siegfried, Diese Zeitschrift, Bd. XXI, S. 361. 
Die Fraktion $\delta$, welche bei weitem die überwiegende Menge der phosphorhaltigen Substanzen des Alkoholextraktes enthält, erweist sich nach Fällung der erwähnten jecorinartigen Substanz vollständig frei von reduzierenden Substanzen.

Sie enthielt bei zwei verschiedenen Darstellungen:

\begin{tabular}{c|c|c|c}
\hline & $\begin{array}{c}\mathrm{P} \\
\%\end{array}$ & $\begin{array}{c}\mathrm{N} \\
\%\end{array}$ & $\mathrm{P}: \mathrm{N}$ \\
& 3,28 & 3,63 & $1: 2,45$ \\
I & 3,01 & 3,53 & $1: 2,59$
\end{tabular}

Es besteht also die Fraktion $\delta$ aus Lecithinen, die einen hohen $\mathrm{N}$-Gehalt aufweisen.

Die Fraktion $\delta$ wurde in Alkohol gelöst und durch alkoholische Chlorcadmiumlösung gefällt; der Chlorcadmiumniederschlag analysiert ergab folgendes Resultat:

$\mathrm{C}=40,35 \% ; \mathrm{H}=6,37 \% ; \mathrm{N}=2,43 \% ; \mathrm{P}=2,62 \% ; \mathrm{Cd}=19,08 \%$; $\mathrm{Cl}=12,13 \% ; \mathrm{P}: \mathrm{N}=1: 2,04$.

Daraus berechnet Erlandsen für dieses Lecithin die Formel:

$$
\mathrm{C}_{40} \mathrm{H}_{75} \mathrm{~N}_{2} \mathrm{PO}_{12} 2 \mathrm{CdCl}_{2} \text {. }
$$

Dieses Lecithin ist also ein Diamidomonophosphatid.

\section{Das Ätherextrakt der Pferdeleber.}

Zur Untersuchung der Phosphatide der Pferdeleber, die beim Extrahieren nach der Erlandsenschen Methode in die Ätherlösung übergehen, wurde die Pferdeleber in kleine Stücke zerschnitten und nach dem im ersten Teile beschriebenen Verfahren getrocknet. Die völlig getrocknete und zu Pulver zer- . riebene Substanz wurde andauernd mit Äther extrahiert, bis derselbe nichts mehr aufnahm. Die gesamten Ätherextrakte wurden in vacuo bis zur Trockene abgedampft. Der Rückstand wurde mit einer geringen Menge reinen Äthers behandelt, wodurch die Hauptmenge aufgelöst wird und leicht von einem unbedeutenden, weißlichen Rest $\left(\mathrm{a}^{\mathrm{I}}\right)$ abfiltriert.

Diese Fraktion $a^{I}$ war von einem ähnlichen Charakter wie die Fraktion a von Erlandsen, d. h. bestand größtenteils aus unorganischen Stoffen.

Die klare, konzentrierte, ätherische Lösung, die schön dunkelrotbraun (mit schmutzig-grüner Farbe fluorescierend) 
war, wurde mit einem vierfachen Volumen Aceton gefällt und einen Tag an einem kühlen Ort stehen gelassen. Der Niederschlag bestand teilweise aus einer dunkelrotbraunen, dicht sirupartigen Substanz, der Hauptmenge des Niederschlages, teilweise aus losen, weißlichen Körnchen, welche sich an den Wänden des Glases absetzten und sich beim Abnehmen vom Glase in eine schmierige, gelbliche Masse verwandelten. Der gesamte Niederschlag wurde dekantiert, mit Aceton gewaschen, das Aceton in vacuo entfernt und der acetonfreie Niederschlag in wasserfreiem Äther gelöst. Die klare Ätherlösung wurde durch das dreifache Volumen absoluten Alkohols gefällt. Es entstand zuerst ein feiner, gelblichweißer Niederschlag, der sich teilweise zusammenballend am Boden setzte. Beim längeren Stehen verwandelte sich der Niederschlag in eine dunkelrotbraune, sirupartige Masse. Diese Masse ging beim Filtrieren durch das Filterpapier. Der Niederschlag wurde samt der Lösung an einem kalten Ort auf 24 Stunden stehen gelassen. Es bildete sich außer dem sirupartigen Niederschlag ein dem oben erwähnten ähnlicher, loser, gelblichweißer Niederschlag. Der gesamte Niederschlag wurde abfiltriert und mit Alkohol gewaschen. Somit wurden die acetonlöslichen Bestandteile des Ätherextraktes in einen alkoholunlöslichen Teil $\mathrm{b}^{\mathrm{I}}$ und alkohollöslichen Teil $\mathrm{C}^{\mathrm{I}}$ (Ätheralkohollösung) getrennt. Diese Fraktionen $b^{I}$ und $C^{I}$ entsprachen den Erlandsenschen Fraktionen $b$ und $C$.

Einzelne Untersuchungen über den Niederschlag $b^{\mathrm{I}}$ haben

- gezeigt, daß die sirupartige Masse auch im warmen Alkohol unlöslich war, während der lose, gelblichweiße Niederschlag im warmen Alkohol sich leicht löste, mit Hinterlassen einer geringen Menge von der sirupartigen Substanz, die zu der ersteren hinzugefügt wurde.

Deshalb wurde der gesamte Niederschlag $b^{\mathrm{I}}$ nach den Angaben von Erlandsen zweimal der Reihe nach mit Alkohol, der auf $60^{\circ}$ erwärmt war, behandelt. Hierbei lösten sich die weißen Körnchen, während die braune Masse ungelöst blieb.

Diese braune Masse $\left(\mathrm{b}^{2} \mathrm{I}\right.$, die in der Wärme sirupartig ist, wurde abfiltriert.

Das alkoholische Filtrat, das etwas gelblich gefärbt war, 
schied nach dem Erkalten einen feinen, weißen Niederschlag (b $1^{\mathrm{I}}$ ) ab.

Dieser Niederschlag (b $\left.1^{\mathrm{I}}\right)$ ist aller Wahrscheinlichkeit nach von derselben Natur wie die Erlands ensche Fraktion $b_{I}$, wurde von mir aber noch nicht näher untersucht.

Die ungelöste braune Masse (b $2^{1}$ ) wurde in geringer Menge absoluten Äthers gelöst und mit wasserfreiem Aceton gefällt. Hierbei entstand ein gelblicher Niederschlag, der sich beim Stehen etwas zusammensetzte. Dieser Niederschlag wurde abfiltriert, von Aceton befreit, in einer geringen Menge heißen Essigesters gelöst und bei niedriger Temperatur stehen gelassen, wodurch $b_{1}^{I}$ als ein bräunlicher Sirup auf dem Boden des Gefäßes sich sammelte.

Nach Dekantierung und Absaugen des restierenden Esters und Trocknen in vacuo löst sich $b_{1}^{I}$ vollständig klar in Äther und wird durch Alkohol quantitativ gefällt. Nach dem Trocknen im Vakuumexsikkator stellt die Substanz eine gelbbraune, transparente Masse dar von harter, fast harziger Konsistenz, die sich leicht zu einem orangegelblichen Pulver zerreiben läßt.

Dargestellt nach denselben Angaben wie das Cuorin, hat die Substanz mit demselben viele Eigenschaften gemeinsam. Die Substanz löst sich in Äther, Chloroform, Petroleumäther und Schwefelkohlenstoff, schwerer in Benzol. Aus der ätherischen Lösung wird sie durch Alkohol quantitativ gefällt. In Wasser quillt sie $\mathrm{zu}$ einer opalisierenden Lösung auf. Die Substanz reduziert nicht Fehlingsche Lösung, selbst nach längerem Kochen mit verdünnter $\mathrm{H}_{8} \mathrm{SO}_{4}$, löst sich mit braungelber Farbe in konzentrierter $\mathrm{H}_{3} \mathrm{SO}_{ \pm}$und giht beim Zusatz oiner 10\% igon Zuckerlösung Pettenk ofers Reaktion. Ebenso wie das Cuorin ist die Substanzautooxydabel. Lange gestandene Präparate weisen eine viel kleinere Hüblersche Zahl auf, als frisch dargestellte, und lösen sich nur noch schwer in Äther auf, leichter dagegen in Wasser.

Abweichend von Cuorin enthält die Substanz kleine Mengen Schwefel und weist einen kleineren Fettsäuregehalt auf als das Cuorin.

Ich habe deshalb der Substanz den Namen Heparphosphatid gegeben.

Huppe-Seyler's Zeitschrift f. physiol. Chemie. LVII. 
Die Analyse des Heparphosphatids gab folgende Zahlen; zum Vergleich sind hier die Analysenzahlen des Cuorins von Erlandsen angeführt:

$\begin{array}{cc}\text { Heparphosphatid Nr. } 1 & \text { Cuorin } \\ \mathrm{C}=61,12 \% & 61,63 \% \\ \mathrm{H}=8,95 \% & 9,03 \% \\ \mathrm{P}=4,00 \% & 4,46 \% \\ \mathrm{~N}=1,23 \% & 1,015 \% \\ \mathrm{O}=(24,04 \%) & 23,86 \% \\ \mathrm{~S}=0,6 \% & \text { fehlt } \\ \mathrm{N}: \mathrm{P}=1: 1,47 & 1: 1,99 \\ \text { Asche }=10,88 \% & -\end{array}$

Elementaranalyse (Verbrennung mit chromsaurem Blei).

1. $0,3111 \mathrm{~g}$ Substanz gaben $0,6956 \mathrm{~g} \mathrm{CO}_{2}=60,98 \% \mathrm{C}$ und $0,2508 \mathrm{~g} \mathrm{H}_{2} \mathrm{O}=8,95 \% \mathrm{H}$.

2. $0,281 \mathrm{~g}$ Substanz gaben $0,6313 \mathrm{~g} \mathrm{CO}_{2}=61,27 \% \mathrm{C}$ und $0,2257 \mathrm{~g} \mathrm{H}_{2} \mathrm{O}=8,94 \% \mathrm{H}$.

Kjeldahlbestimmung: 0,4242 $\mathrm{g}$ Substanz verbrauchten $3,79 \mathrm{ccm}$ $\mathrm{n} / 10-\mathrm{H}_{2} \mathrm{SO}_{4}$ à $0,00139714 \mathrm{~g} \mathrm{~N}=1,25 \% \mathrm{~N}$.

$0,352 \mathrm{~g}$ Substanz verbrauchten $3,05 \mathrm{ccm} \mathrm{n} / 10-\mathrm{H}_{2} \mathrm{SO}_{4}=1,21 \% \mathrm{~N}$.

Phosphorbestimmung nach Woy: 0,4154 g Substanz gaben $0,9596 \mathrm{~g} \mathrm{MoO}_{3} \mathrm{P}_{2} \mathrm{O}_{5}=4,004 \% \mathrm{P}$.

$0,424 \mathrm{~g}$ Substanz gaben $0,9756 \mathrm{~g} \mathrm{MoO}_{3} \mathrm{P}_{2} \mathrm{O}_{5}=3,96 \% \mathrm{P}$.

Schwefelbestimmung (Schmelzen der Substanz mit Soda und Fällen der Lösung durch $\mathrm{BaCl}_{2}$ ): 0,7988 g Substanz gaben 0,033 g BaSO $=0,567 \mathrm{~g} \mathrm{~S}$.

0,8054 g Substanz gaben $0,03628 \mathrm{~g} \mathrm{BaSO}_{4}=0,618 \% \mathrm{~S}$.

$0,728 \mathrm{~g}$ Substanz gaben $0,0792 \mathrm{~g}$ Asche $=10,88 \%$.

Aus der Tabelle ersehen wir, daß die Analysenzahlen des Heparphosphatids denen des Cuorins sehr nahe stehen. Bemerkenswert uveremslmmend slmu die Werle rür $\mathrm{G}, \mathrm{Il}$ und $O$, abweichender die Werte für $N$ und $P$. Während im Cuorin das Verhältnis $\mathrm{N}: \mathrm{P}$ nahe $1: 2$ ist, weist das Heparphosphatid ein Verhältnis auf, das nahe $1: 1,5$ ist. Außerdem enthält die Substanz $0,6^{\circ} \% \mathrm{~S}$.

Im Gegensatz zum Jecorin, das ebenfalls schwefelhaltig ist und ähnliche Löslichkeitsverhältnisse aufweist, enthielt das Heparphosphatid keine reduzierenden Substanzen, es weist einen Aschengehalt von nur 10,88\% auf und besitzt keine Alkalimetalle. 
Aus derselben Pferdeleber, aus der das Heparphosphatid Nr. 1 erhalten war, wurde das Heparphosphatid Nr. 2 gewonnen, mit der Umänderung der Methode, daß der primäre Ätherextrakt direkt ohne vorhergehende Acetonfällung durch Alkohol gefällt wurde. Hierbei entstand ein Niederschlag, der sehr ähnlich dem Jecorinniederschlag war, der aus dem primären Alkoholextrakt (siehe I. Teil) durch Fällen der Ätherlösung mit Alkohol hervorgerufen wurde. Der Niederschlag wurde des weiteren ebenso verarbeitet wie das Heparphosphatid Nr. 1 (Auflösen in Äther, Fällen durch Aceton, Behandlung mit warmem Alkohol usw.). Hierbei wurde eine Substanz erhalten, die identisch dem Heparphosphatid Nr. 1 war. Sie enthielt: $\mathrm{N}=1,2 \% ; \mathrm{P}=3,932 \% ; \mathrm{N}: \mathrm{P}=1: 1,48$.

Kjeldahlbestimmung: 0,2618 g Substanz gaben 2,25 ccm n/10$\mathrm{H}_{2} \mathrm{SO}_{4}$ à $0,00137714 \mathrm{~g} \mathrm{~N}=1,202 \% \mathrm{~N}$.

$0,21 \mathrm{~g}$ Substanz gaben $1,79 \mathrm{ccm} \mathrm{n} / 10-\mathrm{H}_{2} \mathrm{SO}_{4}$ ̀̀ $0,00139 \%=1,196 \% \mathrm{~N}$.

Phosphorbestimmung nach Woy: 0,3766 g Substanz gaben $0,8591 \mathrm{~g} \mathrm{MoO}_{3} \mathrm{P}_{8} \mathrm{O}_{5}$, d. i. $3,932 \% \mathrm{P}$.

Weiter von mir dargestellte Heparphosphatidpräparate wiesen folgenden $\mathrm{P}-, \mathrm{N}$ - und S-Gehalt auf (Präparate Nr. 3 und 4 wurden aus anderen Pferdelebern dargestellt, als das Präparat Nr. 1).

\begin{tabular}{l|c|c|c|c}
\hline \multirow{2}{*}{} & \multicolumn{4}{|c}{ Heparphosphatid } \\
\cline { 2 - 5 } & Nr. 1 & Nr. 2 & Nr. 3 & Nr. 4 \\
\hline P & 4 & 3,93 & 4,01 & 4,45 \\
N & 1,23 & 1,2 & 1,3 & 1,41 \\
S & 0,6 & - & 0,85 & - \\
\hline N : P & $1: 1,47$ & $1: 1,48$ & $1: 1,4$ & $1: 1,428$
\end{tabular}

Proiparat $N r$. 3. Kjeldahlbestimmung: 0,3125 g Substanz verbrauchten $2,9 \mathrm{ccm} \mathrm{n} / 10-\mathrm{H}_{2} \mathrm{SO}_{4}$ à $0,0014034 \mathrm{~g} \mathrm{~N}=1,303 \% \mathrm{~N}$.

$0,421 \mathrm{~g}$ Substanz verbrauchten $3,9 \mathrm{ccm} \mathrm{n} / 10-\mathrm{H}_{2} \mathrm{SO}_{4}=1,30 \% \mathrm{~N}$.

Phosphorbestimmung nach Neumann: 0,3848 g Substanz verbrauchten $28,35 \mathrm{ccm} n / 2-\mathrm{NaHO}=4,02 \% \mathrm{P}$.

$0,1788 \mathrm{~g}$ Substanz verbrauchten $12,88 \mathrm{~cm} \mathrm{n} / 2-\mathrm{NaHO}=3,99 \% \mathrm{~N}$.

Präparat Nr.4. Kjeldahlbestimmung: 0,1984 g Substanz verbrauchten $2 \mathrm{ccm} \mathrm{n} / 10-\mathrm{H}_{2} \mathrm{SO}_{4}$ à $0,0014034 \mathrm{~g} \mathrm{~N}=1,41 \% \mathrm{~N}$. 
Phosphorbestimmung nach Neumann: 0,1645 g Substanz verbrauchten $13,25 \mathrm{ccm} \mathrm{n} / 2-\mathrm{NaHO}=4,45 \% \mathrm{P}$.

Präparat Ni. 3. Schwefelbestimmung nach Carius: $0,2422 \mathrm{~g}$ Substanz gaben $0,01489 \mathrm{~g} \mathrm{BaSO}_{4}-0,00204477 \mathrm{~g} \mathrm{~S}=0,844 \% \mathrm{~S}$.

0,2058 g Substanz gaben $0,0128883 \mathrm{~g} \mathrm{BaSO}_{4}-0,001775568 \mathrm{~g} \mathrm{~S}$ $=0,862 \% \mathrm{~S}$.

Aus der Tabelle sieht man, daß alle 4 dargestellten Präparate einen ziemlich übereinstimmenden $\mathrm{N}$ - und P-Gehalt aufweisen. Abweichender sind die Zahlen für das Präparat Nr. 4. Der Grund dafür scheint darin zu liegen, daß das Präparat Nr. 4 etwas anders als die übrigen Präparate dargestellt wurde. Präparate Nr. 1-3 wurden bei ihrer Darstellung zur Entfernung der Fraktion b2 ${ }^{\mathrm{I}}$, wie oben beschrieben ist, mehrere Male mit auf $60^{\circ}$ erwärmtem Alkohol behundelt, bis der letzte nach $\mathrm{Ab}$ gießen und Erkalten keinen Niederschlag gab. Das Präparat Nr. 4 dagegen wurde mehrere Stunden (4-5) im Wärmeschrank bei $70^{\circ}$ mehrere Mal mit Alkohol behandelt. Das Präparat Nr. 4 war im Vergleich zu den übrigen leichter und vollständig klar in Wasser löslich. Das Verhältnis $\mathrm{N}: \mathrm{P}$ ist in ihm ein ähnliches wie bei den anderen Präparaten.

Das Präparat Nr. 3 wurde ohne die bei Präparat 1 und 2 angewandte schließliche Reinigung durch Auflösung in Essigester dargeslellt. Da ich vermuten konnte, daß durch Ausfällung aus Essigester eine Änderung der Zusammensetzung hervorgerufen werden könne (Erlandsen schreibt nämlich, daß er durch P-Bestimmung im Abdampfungsrückstand der Essigesterlösung sich überzeugt hat, daß die Umfällung aus Essigester wirklich eine Reinigung sei), wurde das Präparat Nr. 3

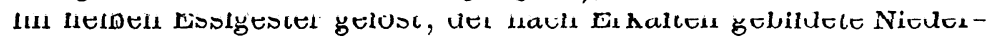
schlag wiederum im Essigester gelöst und der gebildete Niederschlag analysiert. $\operatorname{Er}$ enthielt: $\mathrm{N}=1,302 \% ; \mathrm{P}=4,02 \%$.

Kjeldahlbestimmung: $0,4256 \mathrm{~g}$ Substanz gaben $3,95 \mathrm{ccm} \mathrm{n} / 10-$ $\mathrm{H}_{2} \mathrm{SO}_{4}$ à $0,0014034 \mathrm{~g} \mathrm{~N}=1,302 \% \mathrm{~N}$.

Phosphorbestimmung nach Neumann: 0,3039 g Substanz gaben $22,1 \mathrm{ccm} \mathrm{n} / 2-\mathrm{NaHO}=4,03 \% \mathrm{P}$.

Wir erhielten also ein Präparat von derselben Zusammensetzung wie das Präparat Nr. 3.

Demnach bewirkt die Ausfällung des Heparphosphatids 
aus Essigester keine Reinigung der Substanz und kann bei der Darstellung des Heparphosphatids unterlassen werden.

Erlandsen hat durch seine Methode (siehe diese Arbeit I. Teil, S. 408 und Erlandsen, Diese Zeitschr., Bd.LI, HeftI, S. 104) festgestellt, daß das Cuorin 3 Fettsäureradikale enthält. Die gesamte Fettsäuremenge betrug durchschnittlich 63,92\%. Die Säuren schmolzen bei $42-48^{\circ}$ und zeigten eine Jodzahl (nach $\mathrm{Hübl)}$ von 130,10 , während die Jodzahl von frisch dargestellten Cuorinpräparaten ca. 101 betrug. Aus allen seinen Untersuchungen über die Fettsäurenatur schließt Erlandsen, daß die Säuren ganz oder teilweise der Linolsäurereihe $\left(\mathrm{C}_{\mathrm{n}} \mathrm{H}_{2^{\mathrm{n}-4}} \mathrm{O}_{2}\right)$ oder sogar der Linolensäurereihe $\left(\mathrm{C}_{\mathrm{n}} \mathrm{H}_{2 \mathrm{n}-6} \mathrm{O}_{2}\right)$ gehören.

Das Heparphosphatid dagegen enthält nur ca. 47,5\% Fettsäuren. Die Hüblsche Zahl des Phosphatids beträgt: Präparat Nr. $3-64,31$, Präparat Nr. $1-61,4$; die der freien Säuren - 83,4. Eine ähnliche Jodzahl zeigten auch die freien Fettsäuren aller von mir aus Pferdeleber dargestellten Lecithine.

Es wurde von mir im Heparphosphatid auch das Vorhandensein der Ölsäure nachgewiesen. Daraus könnte man schließen, daß das Heparphosphatid dieselben Fettsäuren enthalte wie das Lecithin der Pferdeleber.

Beim Glühen hinterläßt das Heparphosphatid 10,88\% Asche (0,788 g Substanz gaben 0,0792 g Asche). Da die Substanz keine Alkalimetalle enthält, so muß der ganze Aschegehalt auf $\mathrm{P}$ bezogen werden. Wenn wir die $4 \% \mathrm{P}$ auf Metaphosphorsäure umrechnen, so bekommen wir 10,32\% Metanhnonhorsäure - pine 7,ahl, dis 10,8R (dom Acohogohalt in Prozent) nahe ist.

Aus der Fraktion $\mathrm{C}^{\mathrm{I}}$ des Ätherextraktes der Pferdeleber wurde nach den Angaben von Erlandsen Lecithin dargestellt. Getrocknet stellte es orangegelbe Massen von halbspröder Konsistenz dar, die sich klebrig anfühlten und sich leicht zerteilen ließen. Beim Stehen an der Luft nahm es begierig Wasser an, bis es dickflüssig wurde; es löste sich leicht in Alkohol, etwas schwerer in Äther.

Die Analyse des von mir aus dem Ätherextrakt der Leber dargestellten Lecithins gab folgende Resultate: 


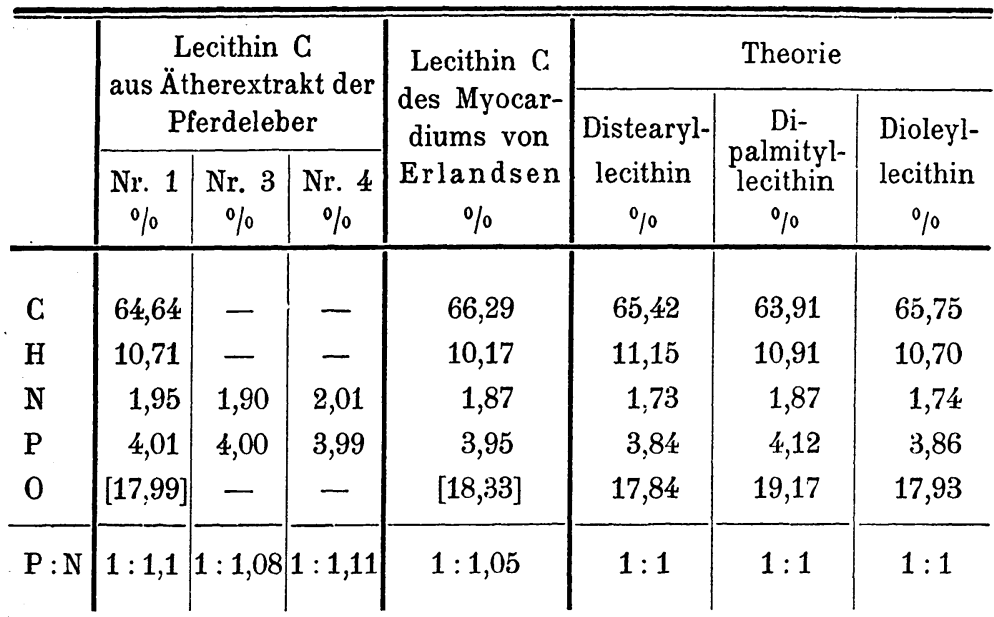

Des Vergleiches halber sind hier in der Tabelle Analysenzahlen des Lecithins $\mathrm{C}$ aus Myocardium von Erlandsen und die Prozentzahlen der Zusammensetzungen der theoretischen Lecithine angeführt.

Lecithin Nr. 1. Elementaranalyse: 0,2125 g Substanz gaben $0,5070 \mathrm{~g} \mathrm{CO}_{2}=64,64 \% \mathrm{C}$ und $0,2032 \mathrm{~g} \mathrm{H}_{2} \mathrm{O}=10,71 \% \mathrm{H}$.

Kjeldahlbestimmung: 0,4261 g Substanz verbrauchten $5,95 \mathrm{ccm}$ $\mathrm{n} / 10-\mathrm{H}_{2} \mathrm{SO}_{4}$ à $0,0014039 \mathrm{~g} \mathrm{~N}=1,95 \% \mathrm{~N}$.

Phosphorbestimmung nach Neumann: 0,3915 g Substanz gaben $23,3 \mathrm{ccm} \mathrm{n} / 2-\mathrm{NaHO}=4,01 \% \mathrm{P}$.

Lecithin Nr. 3. Kjeldahlbestimmung: 0,411 g Substanz verbrauchten $5,7 \mathrm{ccm} \mathrm{n} / 10-\mathrm{H}_{8} \mathrm{SO}_{4}$ à $0,0014034 \mathrm{~g} \mathrm{~N}=1,946 \% \mathrm{~N}$.

0,5021 g Substanz verbrauchten $6,7 \mathrm{ccm} \mathrm{n} / 10-\mathrm{H}_{2} \mathrm{SO}_{4}=1,87 \% \mathrm{~N}$.

Phosphorbestimmung nach Neumann: 0,2295 g Substanz verbrauchten $16,75 \mathrm{ccm} \mathrm{n} / 2-\mathrm{NaHU}=4,04 \% \mathrm{r}$.

$0,1022 \mathrm{~g}$ Substanz verbrauchten $7,32 \mathrm{ccm} \mathrm{n} / \mathbf{2}-\mathrm{NaHO}=3,965 \% \mathrm{P}$.

Lecithin Nr. 4. Kjeldahlbestimmung: 0,3599 g Substanz verbrauchten $5,17 \mathrm{ccm} \mathrm{n} / 10-\mathrm{H}_{2} \mathrm{SO}_{4}$ à $0,0014034 \mathrm{~g} \mathrm{~N}=2,016 \% \mathrm{~N}$.

Phosphorbestimmung nach Neumann: 0,2018 g Substanz verbrauchten $14,55 \mathrm{ccm} \mathrm{n} / \mathrm{s}-\mathrm{NaHO}=3,991 \% \mathrm{P}$.

Aus der obigen Tabelle ersehen wir, daß das aus dem Ätherextrakte der Leber dargestellte Lecithin ein Monoamidomonophosphatid ist, und seiner Zusammensetzung nach sehr nahe kommt dem Erlandsenschen Lecithin $\mathrm{G}$ und dem theoretisch gedachten Lecithin, das im Molekül 1 Atom $\mathrm{N}$ und 
1 Atom $P$ enthält. V́om Erlandsenschen Lecithin $\mathrm{C}$ unterscheidet sich unser Lecithin durch etwas kleineren G-Gehalt und etwas größeren H-Gehalt. Dieser Umstand wird uns aber einigermaßen verständlich, wenn wir uns erinnern, daß das Lecithin $\mathrm{C}$ von Erlandsen eine Hüblsche Zahl, die nahezu 100 war, zeigte; die freien Säuren aber eine Jodzahl von minim. 110 hatten. (Henriquez und Hansen haben für das Eilecithin eine Jodzahl 71,4 gefunden und für die freien Fettsäuren eine Jodzahl von 95-101,6.) Erlandsen spricht dabei die Meinung aus, daß sein Lecithin, wie das Cuorin, überwiegend wasserstoffarme Fettsäuren in sich enthalte. Das von uns dargestellte Lecithin der Pferdeleber dagegen zeigte eine Hüblsche Zahl 72,3; die der freien Säuren aber 84,1, ähnlich wie das Heparphosphatid, d. h. es handelt sich in der Pferdeleber um wasserstoffreichere Fettsäuren, als beim Erlandsenschen Lecithin. Durch diesen Umstand ließe sich auch der kleinere C-Gehalt und größere H-Gehalt unseres Lecithins erklären.

Untersuchung der Spaltungsprodukte des Lecithins und des Heparphosphatids.

Die Zerlegung des Lecithins und des Heparphosphatids in ihre Spaltungsprodukte wurde von mir mit Hilfe der gasförmigen Salzsäure durchgeführt.

$\mathrm{Zu}$ diesem Zwecke wurden 2,062 $\mathrm{g}$ des Lecithins Nr. 3 in überschüssigem absoluten Alkohol gelöst. In die alkoholische Lecithinlösung wurde, zuerst bei gewöhnlicher Temperatur, nachher unter Abkühlung durch Schnee, Salzsäuregas bis zur vollkommenen Übersaturgung der Lơsung curchgeferter. Daraur wurde der Kolben, der die Lösung enthielt, mit einem Propfen verschlossen und einen Tag stehen gelassen. Am nächsten Tage wurde die Lösung auf dem Wasserbade unter Rückfluß gekocht, bis kein Salzsäuregas mehr durch den Kühler entwich.

Durch die Einwirkung des Salzsäuregases beim Kochen der Lösung mußte hierbei nicht nur vollkommene Hydrolyse des Lecithins in seine Spaltungsprodukte, sondern auch die Esterifizierung der freigewordenen thöheren Fettsäuren (Fischersche Reaktion) hervorgerufen werden. 
Die Lösung wurde nun auf dem Wasserbade erwärmt, bis der größte Teil des Alkohols vertrieben war. Darauf wurde zur Lösung ein mehr als 10 faches Volumen Wasser hinzugefügt. Hierbei schieden sich die bei der Hydrolyse des Lecithins durch Einwirkung des Salzsäuregases in Alkohollösung gebildeten Äthylester der Fettsäuren als eine auf dem Wasser schwimmende Schicht ab, während die anderen Spaltungsprodukte, d. h. salzsaures Cholin und Glycerinphosphorsäure, event. freie Phosphorsäure und Glycerin, in Wasser gelöst wurden. $\mathrm{Zu}$ diesem Gemisch wurde $2 / 3$ Volumen Äther hinzugefügt und gut durchgeschüttelt. Hierbei lösten sich die Fettsäureester in Äther auf (bekanntlich dürfen stark salzsaure Lösungen nicht ausgeäthert werden; da hier aber die Lösung nur schwach durch $\mathrm{HCl}$ sauer ist, da beinahe das ganze Salzsäuregas beim Kochen vertrieben wurde, so müßte hier die Ausätherung eine vollkommene sein) und es entstanden 2 deutliche durchsichtige Schichten. Von den beiden deutlich gesonderten Schichten enthielt die obere die Fettsäureester, die untere wässerige alle anderen Spaltungsqrodukte des Lecithins. Nach der Trennung im Scheidetrichter wurde die ätherische Lösung mit Wasser, die wässerige mit Äther mehrere Male durchgespült, und das Waschwasser zur wässerigen Lösung, der Waschäther zur ätherischen Lösung hinzugefügt.

Untersuchung der Fettsäuren.

Zur Bestimmung des Fettsäuregehaltes wurde aus der ätherischen Lösung der Äther verdunstet, die zurückgebliebenen

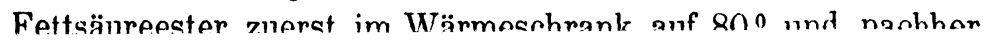
mehrere Tage im vacuo bis zum konstanten Gewicht getrocknet. 2,062 g Lecithin gaben auf solche Weise 1,6118 g Fettsäureester. Diese Ester wurden in Alkohol gelöst, zur Lösung $20 \mathrm{ccm}$ n/2-Natronlauge hinzugefügt und das Ganze zur Verseifung auf dem Wasserbade unter Rückfluß gekocht. Nach völliger Verseifung wurde die Seifenlösung auf einen Liter verdünnt.

In der Seifenlösung wurde durch Titrieren der überschüssigen Natronlauge die Verseifungszahl bestimmt. $\mathrm{Zu}$ diesem $\mathrm{Zwecke}$ wurden von je einem Liter $100 \mathrm{ccm}$ entnommen und mit Phenolphthalein und n/10-Schwefelsäure titriert. 


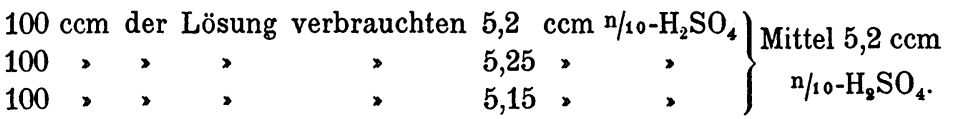

Nun enthielt 11 Fettsäurelösung $20 \mathrm{ccm} \mathrm{n} / 2$-Natronlauge, d. h. $100 \mathrm{ccm}-2 \mathrm{ccm} \mathrm{n} / \mathrm{z}$-Natronlauge; ziehen wir von dieser Menge die den $5,2 \mathrm{ccm} \mathrm{n} / 10-\mathrm{H}_{2} \mathrm{SO}_{4}$ entsprechenden $1,04 \mathrm{ccm} \mathrm{n} / 2-N a t r o n l a u g e ~ a b$, so bekommen wir: $2-1,04=0,96 \mathrm{ccm} \mathrm{n} / 2$-Natronlauge.

$1 \mathrm{ccm} \mathrm{n} / 2$-Natronlauge enthält aber $0,02 \mathrm{~g} \mathrm{Na}(\mathrm{OH})$, demnach ist in $100 \mathrm{ccm}$ der Seifenlösung $0,0192 \mathrm{~g} \mathrm{Na}(\mathrm{OH})(0,96 \mathrm{ccm}$ à $0,02 \mathrm{~g} \mathrm{NaOH})$ an Fettsäuren gefunden.

Die Verseifungszahl ist also $0,192 \mathrm{~g} \mathrm{Na}(\mathrm{OH})$ für die Menge Fettsäureester, die 2,062 g Lecithin entsprechen.

Um die Natur der Fettsäuren näher zu bestimmen, habe ich aus den Natronseifen die Silbersalze der Fettsäuren dargestellt. Es wurden dazu $100 \mathrm{ccm}$ der Seifenlösung mit $\mathrm{n} / 10-$ $\mathrm{H}_{2} \mathrm{SO}_{4}$ neutralisiert und noch ein kleiner Überschuß der Säure hinzugefügt. Die Lösung wurde nun durch Ammoniak alkalisch gemacht und auf dem Wasserbade gekocht, bis das überschüssige freie Ammoniak vertrieben war und die Lösung neutral reagierte. Die neutrale Seifenlösung wurde nun durch Silbernitrat gefällt. Es entstand ein gelblicher voluminöser Niederschlag, der sich bald niedersetzte. Am nächsten Tage wurde der Niederschlag auf einem vorher gewogenen Filter abfiltriert und mit Wasser gewaschen, nachher mit etwas Alkohol. Das Filter wurde nun nebst Niederschlag bis zur Gewichtskonstanz in vacuo getrocknet:

I. $100 \mathrm{ccm}$ von 11 Lösung gaben $0,2000 \mathrm{~g}$ Silbersalze.

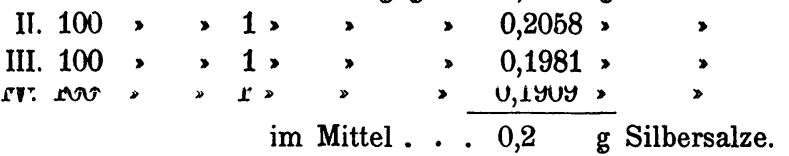

In den Silbersalzen wurde der Silbergehalt durch Verbrennen und Glühen der Substanz im Tiegel und Wägung des metallischen Ag bestimmt. Da ich vermutete, daß bei der Hydrolyse des Lecithins durch $\mathrm{HCl}$ an die dort vorhandene Ölsäure zur Stelle der doppelten Bindung die Elemente des Chlorwasserstoffs sich anlagern könnten und dadurch im Glührückstande außer metallischem Silber noch AgCl vorhanden sein könnte, habe ich das nach dem Glühen im Tiegel zurückgebliebene Silber im Wasserstoffstrom längere Zeit geglüht, darauf ohne Wasserstoff geglüht und nach dem Erkalten gewogen. Die Resultate waren vor und nach dem Glühen im Wasserstoffstrom dieselben. Auch zeigten die Seifen beim 
Glühen auf einem Kupferdraht keine Reaktion auf Chlor (Beilsteinsche Reaktion). Daraus kann man schließen, daß bei den so erhaltenen Seifen keine Elemente des Chlorwasserstoffes zur Ölsäure sich hinzugefügt haben.

Die Silbergehaltsbestimmungen gaben folgende Resultate: $=29,69 \% \mathrm{Ag}$.

1. $0,195 \mathrm{~g}$ Silbersalze (v. Nr. 1) gaben nach dem Glühen $0,0571 \mathrm{~g} \mathrm{Ag}$

2. 0,184 g Silbersalze (v. Nr. 2) gaben nach dem Glühen $0,0568 \mathrm{~g} \mathrm{Ag}$ $=30,87 \% \mathrm{Ag}$.

3. 0,2234 g Silbersalze (v. Nr. 3) gaben nach dem Glühen $0,078 \mathrm{~g} \mathrm{Ag}$ $=30,40 \% \mathrm{Ag}$.

Das eine der Säureradikale war von mir als Ölsäure erkannt worden; ob das andere eine Stearinsäure oder Palmitinsäure ist, konnte von mir nicht entschieden werden, da nach der Abscheidung der Ölsäure die zurückgebliebenen Fettsäuren bei $50^{\circ}$ schmolzen, niedriger als die Schmelzpunkte der beiden genannten Fettsäuren.

Ein Gemisch der Silbersalze der beiden Säuren in äquivalenten Mengen muß folgende Quantitäten $\mathrm{Ag}$. enthalten

Palmitinsäure + Ölsäure $=28,76 \% \mathrm{Ag}$.

Stearinsäure + Ölsäure $=27,67 \% \mathrm{Ag}$.

Unsere Silbersalze enthalten dagegen rund $30 \% \mathrm{Ag}$. Daraus kann man schließen, daß im Lecithin außer der Ölsäure und Stearinsäure (oder Palmitinsäure) noch andere, in der homologen Reihe niedriger stehende Säuren existieren, oder daß vielleicht die Ölsäure bei der Verseifung teilweise an der Stelle ihrer doppelten Bindung in 2 Säuren gespaltet wurde.

Ziehen wir nun von der gefundenen Menge der Silbersalze $(0,2 \mathrm{~g}$, die $100 \mathrm{~cm}$ Seifenlösung, d. h. 0,2062 g Lecithin entsprechen) den Gehalt an Silber $(30 \%)$ ab und fügen die dem Silbergehalt äquivalente Menge Wasserstoff hinzu, so bekommen wir:

$$
\begin{aligned}
& 0,2 \mathrm{~g} \text { Silbersalze } \\
&- 0,06 \mathrm{~g} \text { Silber } \\
& \hline 0,14 \mathrm{~g} \\
&+ 0,0006 \mathrm{~g} \text { Wasserstoff } \\
& \hline 0,1406 \mathrm{~g} \text { Fettsäuren. }
\end{aligned}
$$

$0,2062 \mathrm{~g}$ Lecithin enthält demgemäß 0,1406 g Fettsäuren, also $68,186 \%$ Fettsäuren.

Bei der Verseifung des Lecithins mit Barytwasser nach 
der bekannten Weise habe ich bei demselben Lecithin Nr. 3 $=67,810 / 0$ Fettsäuren gefunden. (1,4498 g Lecithin gaben 0,9832 g Fettsäuren.) ${ }^{1}$ )

Wenn wir jedoch versuchen, die Fettsäuremenge aus der Menge der Ester zu bestimmen, indem wir von der Annahme ausgehen, daß das eine Radikal Ölsäure, das andere Stearinsäure sei, so bekommen wir folgendes:'

der Stearinsäure $\mathrm{C}_{18} \mathrm{H}_{38} \mathrm{O}_{2}$ entspricht der Ester $\mathrm{C}_{20} \mathrm{H}_{40} \mathrm{O}_{2}$

$\begin{array}{lll}\text { der Ölsäure } \mathrm{C}_{18} \mathrm{H}_{34} \mathrm{O}_{2} \gg \mathrm{C}_{36} \mathrm{H}_{70} \mathrm{O}_{4} \text { entspricht der Ester } \mathrm{C}_{40} \mathrm{H}_{78} \mathrm{O}_{4} & \text { Summa .... }\end{array}$

Molekulargewicht $=566,56 \quad$ - $\quad 622,62$

Daraus berechnet sich die den Estern $(1,6118 \mathrm{~g})$ entsprechende Fettsäuremenge nach der Gleichung:

$$
\mathrm{x}=\frac{1,6118 \times 566,56}{0,2262}=1,3781
$$

$2,062 \mathrm{~g}$ Lecithin enthalten demgemäß 1,3781 g Fettsäuren, d. h. $66,83 \%$.

Aus der Verseifungszahl läßt sich die Säuremenge folgendermaßen berechnen:

80 Gewichtsteile $\mathrm{Na}(\mathrm{OH})$ entsprechen 556,56 Gewichtsteilen der Gemenge beider Säuren

$$
\frac{0,0192--(\text { Verseifungszahl) }=\mathrm{x}}{\mathrm{x}=\frac{566,56 \times 0,0192}{80}=0,01354 \mathrm{~g} \text { Fettsäuren }}
$$

$0,2062 \mathrm{~g}$ Lecithin entsprechen 0,01354 g Fettsäuren $=65,71 \%$.

Der Unterschied der aus der Verseifungszahl berechneten Prozentzahl von den anderen berechneten Prozentzahlen ergibt sich daraus, daß das Titrieren der höheren Fettsäuren äußerst schwierig und nicht genau durchzuführen ist.

Zersetzung des Heparphosphatids.

Auf ebendieselbe Weise wie beim Lecithin wurden die Untersuchungen über die Zersetzungsprodukte des Heparphosphatids durchgeführt.

1) Zum Vergleich sei hier ausgeführt, daß

Distearyllecithin $=70,46 \%$

Dipaimityllecithin $=65,25 \%$

Dioleyllecithin $\quad=70,31 \%$ Fettsäuren enthalten muß. 
$\mathrm{Zu}$ diesem Zwecke wurden 1,088 g Heparphosphatid Nr. 3 (von derselben Pferdeleber wie das Lecithin Nr. 3) mit absolutem Alkohol übergossen und durch den Alkohol ein HCl-Strom durchgeleitet. Der Alkohol fing an sich zu färben und nach einiger Zeit ging alles in die Lösung über, die dunkel schwarzrot gefärbt war. Die weitere Behandlung war dieselbe wie die des Lecithins.

Aus der ätherischen Schicht wurde, wie beim Lecithin, die Fettsäureestermenge bestimmt. Die ätherische Lösung hinterließ nach Verdunsten des Äthers und Trocknen des Rückstandes $0,6061 \mathrm{~g}$ Ester. Diese Fettsäureester wurden in Alkohol gelöst; zur Lösung $20 \mathrm{ccm} \mathrm{n/2-Natronlauge} \mathrm{hinzugefügt}$ und die Ester auf dem Wasserbade verseift. Nach der Verseifung wurde zur Lösung in einem graduierten 1/2-Literkolben Wasser bis zur Marke hinzugefügt und zur Bestimmung der Silbersalze von je $1 / 2$ Liter $100 \mathrm{ccm}$ entnommen.

Die Behandlung der Silbersalze war dieselbe wie beim Lecithin:

1. $100 \mathrm{ccm}$ Lösung gaben $0,1468 \mathrm{~g}$ Silbersalz

2. $100 \gg$ Im Mittel . . . $\frac{0,1454 \mathrm{~g}}{0,1461 \mathrm{~g} .}$

Die Bestimmung des Silbergehalts in den Silbersalzen ergab:

1. $0,0981 \mathrm{~g}$ Silbersalz gaben $0,0297 \mathrm{~g} \mathrm{Ag}$. $=30,27 \%$

$2.0,13 \gg, \frac{0,039 \triangleright>=30,00 \%}{\text { rund . . }=30 \% .}$

Wir sehen daraus, daß im Heparphosphatid die Fettsäuren von derselben Natur sind wie im Lecithin. Auch die Jodzahlen für die freien Säuren des Heparphosphatids und des Lecithins stehen einander sehr nahe.

Die Fettsäuren des Heparphosphatids gaben als Jodzahl 83,4

» " Lecithins 》 » 84,1

Ziehen wir nun von der Gewichtszahl der Silbersalze den Silbergehalt ab und fügen die dem Silber äquivalente Menge Wasserstoffe hinzu, so bekommen wir 0,1027 g Fettsäuren; demnach enthält $0,2176 \mathrm{~g}$ Heparphosphatid ( $1 / 2$ Liter Lösung entspricht 1,088 g Heparphosphatid; $100 \mathrm{ccm}=0,2176 \mathrm{~g}$ ) $=0,1027 \mathrm{~g}$ Fettsäuren $=47,19 \%$ Fettsäuren.

Bei der Verseifung des Heparphosphatids Nr. 3 durch Barytwasser wurden $46,92 \%$ Fettsäuren gefunden. 
$1,0685 \mathrm{~g}$ Substanz gaben 0,5014 g Fettsäuren $=46,99 \%$.

Das Heparphoshatid Nr. 1 gab bei der Verseifung durch $\mathrm{Na}(\mathrm{OH}) 47,72 \%$ Fettsäuren.

Wenn wir beim Heparphosphatid dieselbe Annahme machen wie oben, nämlich, daß die Fettsäuren aus Stearinsäure und Ölsäure bestehen, so können wir aus der Fettsäureestermenge den Fettsäuregehalt berechnen:

662,62 Gewichtsteilen Ester entsprechen 566,56 Gewichtsteile Fettsäuren 0,6061 Gewichtsteilen $\mathrm{x}$

$$
\mathrm{x}=0,5182 \mathrm{~g} \text {. }
$$

1,088 g Heparphosphatid enthält 0,5182 $\mathrm{g}$ Fettsäuren $=47,62 \%$ Fettsäuren.

Aus diesen Untersuchungen sieht man, daß das Heparphosphatid dieselben Fettsäuren enthält wie das Lecithin der Pferdeleber, der gesamte Fettsäuregehalt jedoch kleiner ist, als der des Lecithins und des Cuorins.

Untersuchungen über das Cholin.

Nach der Trennung der ätherischen Schicht von der wässerigen wurde die wässerige auf das Cholin und die Glycerinphosphorsäure untersucht.

$\mathrm{Zu}$ diesem $\mathrm{Zwecke}$ wurde die Lösung lange Zeit auf dem Wasserbade gekocht, bis der im Wasser enthaltende Äther vertrieben war. Nach dem Erkalten wurde die Lösung in einen Literkolben gegossen und bis zur Marke verdünnt. Die Bestimmung des Cholins wurde nach der $\mathrm{Stanek}^{1}$ )-Kieselschen ${ }^{2}$ ) Methode durchgeführt. Es wurden von je einem Liter Lösung, welche die in Wasser löslichen Zersetzungsprodukte von 1,062 g Lecithin enthielt, zum Versuch jedesmal $100 \mathrm{ccm}$ Lösung genommen.

Diese $100 \mathrm{ccm}$ Lösung wurden auf dem Wasserbade mehr als zur Hälfte eingeengt und das eine Mal direkt in saurer Lösung durch Kaliumtrijodid gefällt, das andere Mal wurde die Fällung hervorgerufen, nachdem die Lösung durch Natriumbicarbonat alkalisch gemacht wurde. In beiden Fällen erzeugte

1) W. Stanek, Diese Zeitschrift, 1906, Bd. XLVIII, S. 336.

2) Kiesel, Diese Zeitschrift, 1907, Bd. LIII, S. 215. 
das Kaliumtrijodid eine braune, flockige Fällung, die bald in einen krystallinischen Niederschlag, der aus grün schimmernden Blättchen bestand, sich umwandelte. Nach 6 Stunden wurde der Niederschlag durch einen Goochtiegel abfiltriert, mit Wasser gewaschen, nachher samt Asbest in einen Kolben gespült und mit rauchender $\mathrm{H}_{2} \mathrm{SO}_{4}$ nach $\mathrm{Kjeldahl}$ verascht.

Bei der Titration ergab sich folgendes:

1. Für den in saurer Lösung gefällten Niederschlag: $100 \mathrm{ccm}$ Lösung $(0,2062 \mathrm{~g}$ Lecithin) gaben einen Niederschlag, der $1,6 \mathrm{ccm} \mathrm{n} / 10-$ $\mathrm{H}_{2} \mathrm{SO}_{4}$ verbrauchte à $0,0014034 \mathrm{~g} \mathrm{~N}=0,00224544 \mathrm{~g} \mathrm{~N}=1,09 \% \mathrm{~N}$.

2. Der Niederschlag, der in alkalischer Lösung durch Kaliumtrijodid hervorgerufen wurde, verbrauchte ebenfalls $1,6 \mathrm{~cm} \mathrm{n} / 10-\mathrm{H}_{2} \mathrm{SO}_{4}, d$. h. enthielt ebenfalls $0,00224544 \mathrm{~g} \mathrm{~N}$.

Beziehen wir diesen N-Gehalt auf die Gewichtsmengen Lecithin, die $100 \mathrm{ccm}$ Lösung entsprechen, so bekommen wir 1,09\% N. (0,2062 g Lecithin gaben einen Niederschlag, der $0,00224544 \mathrm{~g} \mathrm{~N}$ enthielt).

Rechnen wir nur die Prozente Stickstoffs auf das Cholin um, so bekommen wir 10,96\% Cholin.

Beim zweiten Versuch (es wurden 1,1,3794 $\mathrm{g}$ hydrolysiert) zeigte die Kjeldahlbestimmung ähnliche Zahlen:

Fällung in saurer Lösung: $100 \mathrm{ccm}$ gaben einen Niederschlag, der $1,15 \mathrm{ccm}$ $\mathrm{n} / 10-\mathrm{H}_{2} \mathrm{SO}_{4}$ verbraucht.

Fällung in alkalischer Lösung: $100 \mathrm{ccm}$ gaben einen Niederschlag, der $1,15 \mathrm{ccm} \mathrm{n} / 10-\mathrm{H}_{2} \mathrm{SO}_{4}$ verbraucht, d. h. es wurden hier $1,1 \% \mathrm{~N}$ gefunden oder $11,07 \%$ Cholin.

Da man glauben könnte, daß bei der Fällung des Cholins die Anwesenheit der Glycerinphosphorsäure einen schädlichen Einfluß ausübe, so wurde diese zweite Bestimmung (bei der Verseifung 1,3794) derart geändert, daß die $100 \mathrm{ccm}$ bis zur Trockene abgedampft wurden, der Rückstand mit Alkohol bearbeitet, der das salzsaure Cholin löste; die alkalische Lösung ahgedampft, der Rückstand in Wasser gelöst und in wässeriger Lösung durch Kaliumtrijodid gefällt.

Daraus sehen wir, daß in dem Niederschlag des Cholins, der durch Kaliumtrijodid hervorgerufen wird, anstatt der in Lecithin Nr. 3 vorhandenen $1,9 \% \mathrm{~N}$ nur ca. $1,1 \% \mathrm{~N}$ gefunden oder, auf Cholin berechnet, ca. 11,07\% Cholin, anstatt der 20,52 \% Cholin, die den 1,9\% N entsprechen. Hierbei sei noch erwähnt, daß der N-Gehalt unseres Lecithins $(1,9 \%)$ etwas höher ist, als der N-Gehalt der theoretisch $\mathrm{zu}$ konstruierenden Lecithine. 


\begin{tabular}{l|c|c}
\hline \hline & $\begin{array}{c}\mathrm{N} \\
\%\end{array}$ & $\begin{array}{c}\text { Cholin } \\
\%\end{array}$ \\
\hline Distearyllecithin . . . & 1,73 & 14,99 \\
Dipalmityllecithin . . . & 1,83 & 16,11 \\
Dioleyllecithin . . . . & 1,74 & 15,06 \\
Unser Lecithin . . . . & 1,9 & 11,88 gefunden
\end{tabular}

Moruzzi ${ }^{1}$ ) und Mac Lean') haben die Fällung des Cholins durch Kaliumtrijodid untersucht und der erste im Niederschlag in maximo $77,74 \%$, der zweite in maximo $77,3 \%$ Gholin von der berechneten Cholinmenge gefunden. Erlandsen hat bei seinem Lecithin bei der Fällung des Cholins durch Platinchlorid nur $42 \%$ der berechneten Cholinmenge gefunden. Bei meinen Versuchen enthielt der Niederschlag 58,38\% Cholin von der auf $1,9 \% \mathrm{~N}$ berechneten Cholinmenge und $79,2 \%$ von der im theoretischen Lecithin (Stearyl-oleyllecithin) enthaltenden Cholinmenge.

Aus diesen Tatsachen kann man den Schluß ziehen, daß entweder die Fällung des Cholins durch Kaliumtrijodid keine vollständige ist, oder daß im Lecithin außer dem Cholin andere N-haltige Substanzen existieren, die durch Kaliumtrijodid nicht gefällt werden, eventuell daß in dem Präparat das Cholin teilweise eine Zersetzung oder Veränderung erlitten habe. Meiner Meinung nach hat die zweite Annahme mehr Anhaltspunkte für sich, wie das weiter aus Untersuchungen über Heparphosphatid ersichtlich wird.

Da man meinen Untersuchungen den Einwand machen könnte, daß die erhaltenen Resultate nicht stichhaltig sind, weil die Hydrolyse des Lecithins auf einem neuen Wege, mittels gasformiger $\mathrm{HCl}$, ausgeführt wurde, habe ich zum Vergleich eine Verseifung desselben Lecithins durch Barytlösung bewirkt und aus den Zersetzungsprodukten auf bekanntem Wege eine alkoholische Lösung von kohlensaurem Cholin bekommen. ${ }^{3}$ )

1) Diese Zeitschrift, Bd. LI, S. 113.

2) Diese Zeitschrift, Bd. LV, S. 352.

3) $1,4498 \mathrm{~g}$ verseiften Lecithins gaben bei dieser Gelegenheit $0,989 \mathrm{~g}$ kohlensauren Cholins, d. h. ca. $20 \%$ und $0,2746 \mathrm{~g}$ glycerinphosphorsaures Baryum, d. h. ca. $19 \%$. 
Die Lösung wurde auf dem Wasserbade abgedampft, der Rückstand in Wasser gelöst, die Lösung durch Natriumbicarbonat alkalisch gemacht und durch Kaliumtrijodid gefällt. Der Niederschlag wurde auf oben beschriebenem Wege nach $\mathrm{Kjeldahl}$ auf $\mathrm{N}$ untersucht.

Es waren erforderlich $10,85 \mathrm{ccm} \mathrm{n} / 10-\mathrm{H}_{2} \mathrm{SO}_{4}$ à $0,0014034 \mathrm{~g} \mathrm{~N}, \mathrm{~d}$. h. $=0,01522689 \mathrm{~g} \mathrm{~N}$.

Demnach enthält der Niederschlag nach dieser Darstellungsmethode $=1,05 \% \mathrm{~N}$ auf die verseifte Lecithinmenge $(1,449 \%)$ berechnet, $d . h$. $10,57 \%$ Cholin $(55,3 \%$ der auf $1,9 \% \mathrm{~N}$ berechneten Cholinmenge und $75,6 \%$ der theoretischen Cholinmenge).

Um sicher zu sein, daß der durch Kaliumtrijodid hervorgerufene Niederschlag wirklich ein Cholinniederschlag sei, wurde der Niederschlag in Wasser auf dem Wasserbade mit molekularem Kupfer erwärmt, bis lösliche Jodhydrate sich bildeten. Die letzteren wurden mittels Kupferchlorid in Chlorhydrate verwandelt. Aus diesen wurde das Kupfer durch Schwefelwasserstoff entfernt, die Lösung vom Kupfersulfid abfiltriert und bis zur Trockne abgedampft. Der Rückstand in Wasser gelöst und durch Platinchlorid gefällt. Der Niederschlag diente zur Platinbestimmung. Es wurden 31,36\% Platin gefunden. Das Cholinplatinchlorid enthält berechnet für $\left(\mathrm{C}_{5} \mathrm{H}_{14} \mathrm{NOCl}\right) \mathrm{PtCl}$ - 31,64\% Pt.

\section{$0,1221 \mathrm{~g}$ Substanz gaben $0,0383 \mathrm{~g} \mathrm{Pt}=31,36 \%$.}

Da in dem durch Kaliumtrijodid erzeugten Niederschlage von Cholin nur ca. 58\% der auf $1,9 \% \mathrm{~N}$ berechneten Cholinmenge gefunden wurde, so mußte im Filtrat eine andere $\mathrm{N}$ haltige Substanz sich befinden, die durch Kaliumtrijodid nicht gefällt wurde. Zur näheren Untersuchung wurde das Filtrat und die Waschwasser in einem großen Kolben von Jenaerglas gesammelt und mit rauchender Schwefelsäure stark sauer gemacht; das Wasser abgedampft (wobei violette Joddämpfe entwichen) und schließlich nach Kjeldahl zur N-Bestimmung verbrannt.

Das eine Filtrat stammte von alkalischen, das andere von der sauren Kaliumtrijodid-Fällung in $100 \mathrm{ccm}$ der Verseifungsprodukte von 2,062 $\mathrm{g}$ Lecithin (1. Versuch).

Kjeldahlbestimmung in alkalischer Lösung: es wurden $1,19 \mathrm{ccm}$ $\mathrm{n} / 10-\mathrm{H}_{2} \mathrm{SO}_{4}$ à $0,0014034 \mathrm{~g} \mathrm{~N}$ verbraucht $-0,00166346 \mathrm{~g} \mathrm{~N}=0,809 \% \mathrm{~N}$.

In saurer Lösung: $1,25 \mathrm{ccm} \mathrm{n} / 10-\mathrm{H}_{2} \mathrm{SO}_{4}$ verbraucht $=0,00165495 \mathrm{~g} \mathrm{~N}$ $=0,851 \% \mathrm{~N}$. 
Über Jecorin und andere lecithinartige Produkte der Pferdeleber. 445

Wir sehen daraus, daß im Filtrat vom Cholinniederschlage irgend eine andere $\mathrm{N}$-haltige Verbindung, wahrscheinlich basischer Natur, sich befindet, vorausgesetzt, daß die Fällung des Cholins durch Kaliumtrijodid eine vollständige ist, was kaum bezweifelt werden kann. Diese $\mathrm{N}$-haltige Verbindung enthält ca. $0,8 \% \mathrm{~N}$ auf die verseifte Lecithinmenge bezogen. Fügen wir die erhaltenen Prozentzahlen zu den Prozentzahlen des $\mathrm{N}$ im Cholinniederschlage, so bekommen wir:

\begin{tabular}{r|l|l}
\hline & $\begin{array}{l}\mathrm{N} \\
\%\end{array}$ & $\begin{array}{l}\mathrm{N} \\
\%\end{array}$ \\
\hline Im Niederschlag . . . & 1,09 & 1,09 \\
Im Filtrat . . . . . & 0,809 & 0,851 \\
\hline In Summa . . . & 1,899 & 1,941
\end{tabular}

Wir erhalten also in Summa die 1,9\% N, die das Lecithin Nr. 3 enthält.

Bestimmung des Cholins in Heparphosphatid.

Nach derselben Methode, wie beim Lecithin, wurden auch die Zersetzungsprodukte des Heparphosphatids auf das Cholin untersucht.

Die wässerige Lösung der Zersetzungsprodukte des Heparphosphatids Nr. 3 (1,088 g) wurde bis zu einem Liter verdünnt, jedesmal zum Versuch $200 \mathrm{ccm}$ (entspr. 0,2176 g Heparphosphatid) entnommen und das eine $\mathrm{Mal}$ in alkalischer, das andere Mal in saurer Lösung durch Kaliumtrijodid gefällt. Der Niederschlag nach $\mathrm{Kjeldahl}$ auf $\mathrm{N}$ untersucht. Es wurde verbraucht: 1. $0,6 \mathrm{ccm} \mathrm{n} / 1_{0}-\mathrm{H}_{2} \mathrm{SO}_{4}, 2$. $0,7=$ Mittel $0,65 \mathrm{ccm}$ $\mathrm{n} / 10-\mathrm{H}_{2} \mathrm{SO}_{4}$ à $0,0014034 \mathrm{~g} \mathrm{~N}$, somit wurden $0,001221 \mathrm{~g} \mathrm{~N}$ aus 0,2176 g Heparphosphatid, d. h. nur 0,419\% $\mathrm{N}$ im Niederschlage gefunden, entsprechend 4,22\% Cholin.

Die Filtrate von den Cholinniederschlägen wurden ebenfalls auf $\mathrm{N}$ nach Kjeldahl untersucht. Sie verbrauchten: 1. $1,6 \mathrm{ccm}, 2$. $1,65 \mathrm{ccm}$, im Mittel $1,6 \mathrm{ccm} \mathrm{n} / 10-\mathrm{H}_{2} \mathrm{SO}_{4}$ d. h. $0,00224542 \mathrm{~g} \mathrm{~N}$.

Auf die verseifteHeparphosphatidmenge berechnet $1,03 \% \mathrm{~N}$. 
also ergibt $\operatorname{sich} 0,419 \% \mathrm{~N}$ im Niederschlage, 1,03=im Filtrat, Summa 1,45\% N: Das Heparphosphatid Nr. 3 enthält aber $1,3 \% \mathrm{~N}$.

Hierbei sei noch bemerkt, daß die N-Bestimmung in Narmen Verbindungen nach Kjeld a hlimmer etwas zu hohe Werte für $\mathrm{N}$ gibt, wenn beim Versuch die Anzahl der beim Titriren verbrauchten Kubikzentimeter $\mathrm{n} / \mathbf{1 0}-\mathrm{H}_{2} \mathrm{SO}_{4}$-Lösung gering ist. Deshalb ist wahrscheinlich auch bei unserem Versuch die N-Bestimmung höher ausgefallen, als der Cholinniederschlag in Wirklichkeit $\mathrm{N}$ enthielt, d. h. das Heparphosphatid enthält noch weniger Cholin (wahrscheinlich Spuren), als unsere Analyse gezeigt hat.

Aus diesen Angaben sieht man, daß das Heparphosphatid im Vergleich zum Lecithin nur geringe Mengen von Cholin enthält, und daß die Hauptmenge des Stickstoffs nicht in Form von Cholin vorhanden ist, sondern in einer anderen, durch Kaliumtrijodid nicht fällbaren Verbindung, oder man kann annehmen, daß diese N-haltige Verbindung Umwandlungsprodukt des Cholins ist. Daß die Hauptmenge der N-haltigen Verbindungen des Heparphosphatids nicht Cholin ist, wird besonders aus folgendem Versuch ersichtlich.

$1,0685 \mathrm{~g}$ Heparphosphatid wurden durch Barytlösung verseift. Nach dem Abfiltrieren der Barytseifen und Fällung des überschüssigen Baryts durch Kohlensäure wurde die filtrierte Lösung, die beim Lecithin das kohlensaure Cholin und die Glycerinphosphorsäure enthält, auf dem Wasserbade bis zur Trockne abgedampft. Der Rückstand wurde mit absolutem Alkohol behandelt. Während beim Lecithin in die Alkohollösung bei dieser Gelegenheit bedeutende Mengen von Cholin übergehen, war hier die Alkohollösung kaum gefärbt und hinterließ nach Abdampfen des Alkohols und Trocknen des Rückstandes bis zur Gewichtskonstanz eine nur geringe Menge von Cholin, nämlich 0,029 $\mathrm{g}$ kohlensaures Cholin d. h. 2,7\% der verseiften Heparphosphatidmenge (Lecitin gab ca. 20\% kohlensaures Cholin). In diesen Cholinmengen wurde der Stickstoff nach Kjeldahl bestimmt.

Es wurden $2,15 \mathrm{ccm} \mathrm{n} / 10-\mathrm{H}_{2} \mathrm{SO}_{4}$ verbraucht - 0,00307731 g $\mathrm{N}=0,288 \% \mathrm{~N}$ (der verseiften Heparphosphatidmenge). 
$\mathrm{Daß}$ es wirklich Cholin war, davon überzeugte ich mich durch Bildung von Platindoppelsalz und Untersuchung der Krystallform; zur Bestimmung des Platingehaltes war die erhaltene Menge viel zu gering.

Der nach Alkoholextraktion zurückgebliebene Teil des obenerwähnten Abdampfungsrückstandes der wässerigen Lösung löste sich auch in Aether nicht, jedoch leicht und klar in Wasser. Getroknet nach der Extraktion des Cholins, wog er 0,5976 g (ca. 56\% der verseiften Heparphosphatidmenge; beim Lecithin ca. 19\%). Die Substanz zeigte deutlich N- und P-Reaktion an. Es ließ sich in ihr Glycerin nachweisen. Sie enthielt also glycerinsphorphorsaures Baryum und eine N-haltige Verbindung, die in Wasser leicht löslich war.

Hieraus sehen wir, daß im Heparphosphatid der basische Bestandteil, der Hauptmenge nach, nicht durch Cholin, sondern durch eine andere N-haltige Substanz repräsentiert wird.

\section{Bestimmungen des Glycerins.}

Zum Schlusse suchte ich unter den Zersetzungsprodukten des Lecithins und Heparphosphatids das Glycerin der Glycerinphosphorsäure nach der Methode von Fanto und Zeisel ${ }^{1}$ ) zu bestimmen.

$\mathrm{Zu}$ diesem Zwecke wurden von 1 Liter Lösung der wasserlöslichen Zersetzungsprodukte des Lecithins, die durch Hydrolyse mittels $\mathrm{HCl}$ erhalten wurden, $200 \mathrm{ccm}$ entnommen. Diese $200 \mathrm{ccm}$ Lösung, die durch $\mathrm{HCl}$ sauer war, wurden auf dem Wasserbade bis zur Trockne abgedampft; der trockne Rückstand mit absolutem Alkohol, der das salzsaure Cholin löste, behandelt; der unlösliche Teil wurde nun auf dem Wasserbade zum Verdrängen des Alkohols erwärmt, darauf wieder in Wasser gelöst und auf dem Wasserbade bis zur Trockne abgedampft. Der trockne Rückstand, der nun ganz frei war von $\mathrm{HCl}$ und Alkohol, wurde in wenig Wasser gelöst und sorgfältig in das Siedekölbchen des Fanto-Zeis elschen Apparats gespült, und die Lösung auf dem Wasserbade bis auf $5 \mathrm{ccm}$ ein-

1) Zeitschrift für analyt. Chemie 1903, Bd. XLII, S. 549. 
geengt. Die Bestimmung der Clycerinmenge in diesen $5 \mathrm{ccm}$ Lösung geschah in der Weise, daß zur Lösung $15 \mathrm{ccm}$ konzentrierte Jodwasserstroffsäure hinzugefügt, und das Gemenge bis zum Sieden erhitzt wurde, wobei durch den ganzen Apparat ein Kohlensäurestrom durchgeleitet wurde. Die gebildeten Jodisopropyldämpfe, die aus dem aufrecht stehenden Kühler entwichen, wurden zur Reinigung von mitgerissenen Jodwasserstoffdämpfen durch eine Wasserflasche, die roten Phosphor unter Wasser enthielt, geleitet und schließlich in eine alkoholische Lösung von Silbernitrat geleitet. Aus dem gebildeten Niederschlage wurde nun auf bekanntem Wege die Jodsilbermenge bestimmt und durch Multiplizieren der Jodsilbermenge mit dem Faktor .0,3922 die Glycerinmenge.

Auf dem beschriebenen Wege wurden im Lecithin Nr. 3 $6,39 \%$ Glycerin gefunden, $0,267 \%$ Lecithin gaben $0,0535 \mathrm{~g}$ AgJ d. i. 0,0170602 g Glycerin $=6,39 \%$.

Der Theorie nach enthält das Lecithin 11,4\%. Diesen so bedeutenden Unterschied zwischen mëner Bestimmung und der Theorie habe ich dem Umstand zugeschrieben, daß bei der Hydrolyse des Lecithins durch gasförmiges $\mathrm{HCl}$ die unter den Zersetzungsprodukten befindliche Glycerinphosphorsäure in Glycerin und Phosphorsäure gespalten sei, und daß das Glycerin zum Teil in den Alkoholextrakt übergegangen und dadurch der Bestimmung entgangen sei. Durch einzelne Proben wurde wirklich unter den Zersetzungsprodukten freie Phosphorsäure von mir nachgewiesen.

Ich habe daher die Bestimmungsmethode auf folgende Weise geändert. Von dem Liter Lösung, die das salzsaure Cholin und die Glycerinphosphorsäure enthielt, wurden $200 \mathrm{ccm}$ auf dem Wasserbade bis zur Trockne abgedampft, ohne vorhergehende Alkoholbehandlung sofort in wenig Wasser gelöst, in das Siedekölbchen des Apparats gespült und bis $5 \mathrm{ccm}$ eingeengt. $\mathrm{Da}$ hier keine Alkoholextraktion des Cholins vorgenommen wurde, so mußte in diesen $5 \mathrm{ccm}$ Lösung die ganze im Lecithin vorhandene Glycerinmenge, auch falls eine Spaltung der Glycerinphosphorsäure in ihre Bestandteile vorgegangen war, zugegen sein. Dafür aber mußte hier auch das salzsaure Cholin zu- 
gegen sein. Die im letzteren vorhandene Salzsäure mußte einen störenden Einfluß auf die Glycerinbestimmung haben, da die bei der Einwirkung der Jodwasserstoffsäure freigewordene Salzsäure durch den Kühler und die Waschflasche in die Silbernitratlösung eindringen und daselbst einen Chlorsilberniederschlag hervorrufen mußte, der die Glycerinbestimmung unmöglich macht. Um dieses zu vermeiden, wurde in dem FantoZeis elschen Apparat zwischen der Anlage mit Silbernitratlösung und der Waschflasche mit Phosphor noch eine Waschflasche mit Sodalösung eingeschaltet, die die Salzsäure binden sollte.

Der Siedekolben wurde auf dem Sandbade bis zum Sieden erhitzt; dabei wurde streng darauf geachtet, daß die Temperatur $160^{\circ}$ nicht überstieg. Der in der Silbernitratlösung gebildete Niederschlag wurde abfiltriert, getroknet und gewogen.

Auf diese Weise wurde im Lecithin 10,61\% Glycerin bestimmt.

$0,247 \mathrm{~g}$ Lecithin gaben $0,0722 \mathrm{~g} \mathrm{AgJ}$, d. i. $0,0283168 \mathrm{~g}$ Glycerin $=10,61 \%$, eine Zahl, die der theoretischen $11,4 \%$ nahe kommt.

Der Versuch der Glycerinbestimmung nahm bei $160^{\circ}$ 2-3 Stunden in Anspruch, in der letzten Stunde war keine Vermehrung des Niederschlages bemerkbar. Nach Beendigung der Glycerinbestimmung wurde zur Kontrolle eine neue Vorlage mit Silbernitratlösung eingefügt und die Temperatur des Sandbades allmählich erhöht. Erst als die Temperatur auf $220^{\circ}$ gestiegen war, fing die Silberlösung an sich zu trüben, und bald sammelte sich ein gelblicher Niederschlag. Dieser Niederschlag stammt wahrscheinlich von den Zersetzungsprodukten des Cholins. Bekanntlich werden die organischen Ammoniumbasen durch rauchende Jodwasserstoffsäure bei $200-300^{\circ}$ zerlegt unter Bildung von Jodalkylen. Letztere aber geben mit Silbernitrat einen Niederschlag.

\section{Glycerinbestimmung im Heparphosphatid.}

Ebendieselben Versuche wurden von mir auch mit Heparphosphatid vorgenommen. Hierbei erhieltich folgende Resultate. Nach der ersten Versuchsmethode, d. h. nach vorhergehender Alkoholextraktion des Cholins, wurden 7,81\% Glycerin im Heparphosphatid gefunden. 
$0,2816 \mathrm{~g}$ Substanz gaben $0,0566 \mathrm{~g}$ AgJ, d. i. $0,02219852 \mathrm{~g}$ Glycerin $=7,81 \%$.

Nach dem zweiten Verfahren wurden jedoch $10,12 \%$ Glycerin erhalten.

$0,2816 \mathrm{~g}$ Substanz gaben $0,0726 \mathrm{~g} \mathrm{AgJ}$, d. i. $0,2849372 \mathrm{~g}$ Glycerin $=10,12 \%$.

Nach der Erhöhung der Temperatur auf $220^{\circ}$ wurde auch hier in der Silberlösung ein gelblicher Niederschlag erhalten.

Glycerinmenge in Prozenten:

\begin{tabular}{c|c|c|c}
\hline \hline $\begin{array}{c}\text { Theorie } \\
\text { bei Lecithin } \\
\%\end{array}$ & Lecithin & Heparphosphatid &. \\
\hline & $\%$ & $\%$ & \\
\hline 11,4 & 6,39 & 7,81 & nach der 1. Methode \\
& 10,61 & 10,12 & nach der 2. Methode
\end{tabular}

Aus allen diesen Ergebnissen ersehen wir, daß im Ätherextrakt der Pferdeleber ein Phosphatid sich befindet, welches sich vom Lecithin durch sein andersartiges Verhältnis $\mathrm{N}: \mathrm{P}$, durch seinen niedrigeren Fettsäuregehalt und die Anwesenheit von Schwefel unterscheidet. Der $\mathrm{N}$ ist im Heparphosphatid in anderer Form enthalten, als im Lecithin. Während im Lecithin hauptsächlich Cholin vorhanden ist, enthält das Heparphosphatid, wie es scheint, eine andere $\mathrm{N}$-haltige Verbindung, die von mir noch nicht bestimmt werden konnte. Die Glycerinmenge scheint eine ähnliche $\mathrm{zu}$ sein, wie beim Lecithin.

Zum Schluß sei noch erwähnt, daß das Heparphosphatid (abweichend vom Cuorin, welches stark hygroskopisch ist) weniger hygroskopisch ist als das Lecithin. Während das Lecithin beim Stehen an der Luft leicht Wasser anzieht und dickflüssig wird, kann das Heparphosphatid lange Zeit an der Luft bleiben, ohne bemerkbar Wasser anzuziehen.

Demnach müßte man die hygroskopische Beschaffenheit des Lecithins der Anwesenheit von Cholin, das bekanntlich stark hygroskopisch ist, zuschreiben. In Wasser ist das Heparphosphatid nur schwer und recht trübe löslich. Jedenfalls ist es schwerer wasserlöslich als das Jecorin. 
Über Jecorin und andere lecithinartige Produkte der Pferdeleber. 451

Zum Schluß sei noch hervorgehoben, daß die von mir angewandte Methode der Hydrolyse, Zersetzung durch gasförmige Salzsäure, sich als sehr vorteilhaft erwiesen hat, da die Hydrolyse eine vollständige war und sich viel schneller ausführen ließ als die Verseifung mittels Barytlösung. Die Fettsäurebestimmung war ebenso genau wie bei der Barytverseifung und ließ sich bequemer als letztere ausführen; das Cholin wurde direkt zu weiteren Uutersuchungen in bequemer Form, nämlich als Chlorhydrat erbalten. Da das Cholin sich in salzsaurer Lösung befand, so war keine Gefahr vorhanden, daß es beim Kochen usw. sich zersetzte und teilweise verflüchtigte.

Die Glycerinbestimmungen waren ebenfalls genügend ausgefallen.

Sekundäres Alkoholextrakt der Pferdeleber (nach Erlandsen).

Nach beendigter Ätherextraktion der Pferdeleber wurde dieselbe einer zweiten Extraktion mit 96\% igem Alkohol nach den Angaben von Erlandsen unterworfen. Die vereinigten Alkoholextrakte wurden in vacuo abgedampft, der Abdampfungsrückstand in wenig Alkohol gelöst.

Dabei blieb ein gelblichweißer Niederschlag zurück, welcher, abfiltriert, an der Luft bald Wasser anzog und sich bräunlich färbte. Diese Fraktion entspricht der Erlan d senschen Fraktion $\alpha$. Diese Fraktion scheint ebenso wie die Erlandsensche größtenteils aus unorganischen Stoffen zu bestehen; abweichend von Erlands en dagegen reduziert sie stark die Fehling sche Lösung.

Das alkoholische Filtrat wurde nun bis zur Trockne abgedampft und der Rückstand mit Äther behandelt, in dem er sich löste unter Hinterlassung eines bedeutenden weißlichen Niederschlages. Dieser Niederschlag wurde abfiltriert und zur Reinigung mehrere Male gut mit Äther geschüttelt. Beim Stehen an der Luft wurde der Niederschlag klebrig, honiggelb und schließlich braun. Getrocknet stellt er eine harte, hellbraune Masse dar, die sich jedoch nur schwierig zu Pulver zerreiben läßt. Die wässerige Lösung gibt keinen Niederschlag mit wäs- 
seriger Chlorcadmiumlösung, während die Lösung in verdünntem Alkohol von alkoholischem Chlorcadmium gefällt wird. Die Substanz zeigt N-, P- und S-Reaktion.

Abweichend von der Erlandsenschen Fraktion $\beta$ reduziert die Substanz die Fehlingsche Lösung und besitzt einen höheren P-Gehalt und etwas niedrigeren N-Gehalt. Die Analyse gab folgende Resultate: $\mathrm{N}=4,17 \% ; \mathrm{P}=2,51 \%$; Glykose $=6,2 \% ;$ Asche $=7,79 \% ; \mathrm{P}: \mathrm{N}=1: 3,68$.

Kjeldahlbestimmung: $0,2707 \mathrm{~g}$ Substanz verbrauchten $8,07 \mathrm{ccm}$ $\mathrm{n} / \mathbf{1 0}-\mathrm{H}_{2} \mathrm{SO}_{\text {\& }}$ à $0,00139714 \mathrm{~g} \mathrm{~N}=0,011274919 \mathrm{~g} \mathrm{~N}=4,16 \% \mathrm{~N}$.

$0,3383 \mathrm{~g}$ Substanz verbrauchten $10,13 \mathrm{ccm} \mathrm{n} / 10-\mathrm{H}_{2} \mathrm{SO}_{4}=4,18 \%$.

Phosphorbestimmung $\mathrm{nach}$ Woy: 0,342 $\mathrm{g}$ Substanz gaben $0,4982 \mathrm{~g} \mathrm{MoO}_{3} \mathrm{P}_{2} \mathrm{O}_{5}=2,5 \% \mathrm{P}$.

$0,4359 \mathrm{~g}$ Substanz gaben $0,6425 \mathrm{~g} \mathrm{MoO}_{3} \mathrm{P}_{2} \mathrm{O}_{5}=2,52 \% \mathrm{P}$.

Glykosebestimmung: $0,1788 \mathrm{~g}$ Substanz gaben $0,0111 \mathrm{~g} \mathrm{Cu}$ $=0,0061 \mathrm{~g}$ Glykose $=6,2 \%$ Glykose.

Aschebestimmung: $3,8929 \mathrm{~g}$ Substanz gaben $0,3034 \mathrm{~g}$ Asche $=7,79 \%$.

Rechnet man die 2,51\% $\mathrm{P}$ auf Metaphosphorsäure um, so bekommt man 6,47\% Metaphosphorsäure,

$$
\text { Rest: } \begin{aligned}
& \begin{array}{l}
7,79 \% \\
6,47 \%
\end{array} \text { Asche } \\
1,32 \% &
\end{aligned}
$$

Der Rest fällt wahrscheinlich auf die Alkalimetalle.

Die Substanz enthält Fettsäuren.

Auf Grund des Beschriebenen ist die Substanz als eine jecorinähnliche $\mathrm{zu}$ bezeichnen (sie enthält außer $\mathrm{N}$ und $\mathrm{P}$ noch Glykose, S, Na) und hat ihrer Zusammensetzung nach Ähnlichkeit mit dem in Äther unlöslichen Jecorin, das jedesmal, bei der Reinigung des rohen Jecorinproduktes des primären Alkoholextrakts durch Auflösen in Äther und Fällen mit Alkohol, in Äther unlöslich bleibt und auf diese Weise dem Endprodukt, d. h. dem reinen Jecorin, entzogen wird (siehe I. Teil, Versuch V Seite 419) und dem rohen Jecorin Nr. 2.

Was die Ätherlösung, die von der Fraktion $\beta^{\mathrm{I}}$ abfiltriert wurde, anbetrifft, so haben einzelne Proben gezeigt, daß in derselben durch Aceton wohl ein Niederschlag hervorgerufen wurde, derselbe sich aber nicht, wie bei Erlandsen, völlig in Alkohol 
lösen ließ. Deshalb wurde die Erlandsensche Methode folgendermaßen geändert:

Die Ätherlösung wurde eingeengt und durch Aceton gefällt. Der Niederschlag wurde in Äther gelöst und zur Lösung Alkohol hinzugefügt. Es entstand ein gelblichbrauner Niederschlag, der dem Jecorin sehr ähnlich war. Abweichend von dem Drechselschen Jecorin war der Niederschlag wenig in Äther löslich, löste sich dagegen vollkommen klar in Wasser. Getrocknet stellte er eine braune, spröde Masse dar, die sich zu einem gelblich-hellbraunen Pulver zerreiben ließ. Die Substanz war äußerst hygroskopisch, viel hygroskopischer als das Drechselsche Jecorin. Wie das Drechselsche Jecorin war auch diese Substanz S-haltig.

Die Analyse gab folgende Zahlen:

$\mathrm{N}=4,703 \% ; \mathrm{P}=1,93 \% ;$ Glykose $=13,09 \% ; \mathrm{P}: \mathrm{N}$ $=1: 5,07$.

Kjeldahlbestimmung:0,1928 g Substanz gaben $6,49 \mathrm{ccm}$ n/10- $-\mathrm{H}_{8} \mathrm{SO}_{4}$ à $0,00139714 \mathrm{~g} \mathrm{~N}=4,703 \% \mathrm{~N}$.

Phosphorbestimmung nach Woy: 0,1839 g Substanz gaben $0,2067 \mathrm{~g} \mathrm{MoO} \mathrm{P}_{2} \mathrm{O}_{5}=1,93 \% \mathrm{P}$.

Glykosebestimmung: 0,1634 g Substanz gaben 0,042 $\mathrm{g} \mathrm{Cu}$ $=0,0241 \mathrm{~g}$ Glykose $=13,09 \%$ Glykose.

Diese Fraktion entspricht ihrer Darstellungsweise nach der Erlandsenschen Fraktion $r$. Diese Fraktion wurde von Erlandsen als eine jecorinähnliche anerkannt, da sie $\mathrm{P}-, \mathrm{N}-$ und S-haltig ist und die Fehlingsche Lösung deutlich reduziert. $\mathrm{Da}$ die von uns erhaltene Substanz ebenfalls dieselben Eigenschaften aufweist, so muß auch sie als jecorinartig angesehen werden.

Ein zweites derartiges Präparat wurde aus einer anderen Pferdeleber nach derselben Methode dargestellt, nur wurde die Alkoholextraktion hier nicht mit 96\% igem, sondern mit 85\% igem Alkohol vorgenommen. Das hierbei erhaltene Jecorin zeigte folgende Zahlen:

$\mathrm{N}=7,00 \% ; \mathrm{P}=1,4 \% ;$ Glykose $=21,53 \% ;$ Asche $=8,74 \%$.

Kjeldahlbestimmung: 0,1752 $\mathrm{g}$ Substanz verbrauchten $8,7 \mathrm{ccm}$ $\mathrm{n} / 10-\mathrm{H}_{8} \mathrm{SO}_{4}$ à $0,0014034 \mathrm{~g} \mathrm{~N}=7,05 \% \mathrm{~N}$.

$0,2463 \mathrm{~g}$ Substanz verbrauchten $12,16 \mathrm{ccm} \mathrm{n} / 10-\mathrm{H}_{2} \mathrm{SO}_{4}=6,95 \% \mathrm{~N}$. 
Phosphorbestimmung nach Neumann: 0,2262 g Substanz verbrauchten $5,95 \mathrm{ccm} \mathrm{n} / 2-\mathrm{NaHO}$, d. i. $1,457 \% \mathrm{P}$.

$0,6353 \mathrm{~g}$ Substanz verbrauchten $15,42 \mathrm{~cm} \mathrm{n} / 2-\mathrm{NaHO}$, d. i. $1,34 \%$.

Glykosebestimmung: $0,1939 \mathrm{~g}$ Substanz gaben $0,0815 \mathrm{~g} \mathrm{Cu}$ $=0,04173 \mathrm{~g}$ Glykose $=21,53 \%$.

Aschebestimmung: 0,34 g Substanz gaben 0,0297 g Asche $=8,735 \%$ Asche.

Wenn wir die $1,4 \% \mathrm{P}$ auf $\mathrm{HPO}_{3}$ umrechnen, so bekommen wir $3,612 \% \quad \mathrm{HPO}_{3}$.

$$
\begin{aligned}
& \text { 8,735\% Asche } \\
& 3,612 \% \mathrm{HPO}_{3} \\
& \hline 5,123 \% \text { Rest. }
\end{aligned}
$$

Aus der Anwesenheit des angeführten Restes können wir schließen, daß dieses Jecorin beträchtliche Mengen von unorganischen Substanzen enthält. Der größere Gehalt des Jecorins Nr. 2 an N, der etwas kleinere Gehalt an $\mathrm{P}$ und der größere Gehalt an Glykose erklärt sich wahrscheinlich durch den Umstand, daß die Extraktion hier durch einen mehr wasserhatigen Alkohol vorgenommen wurde $(85 \%)$ als beim Jecorin Nr. 1.

Beide jecorinartigen Substanzen enthielten nur Spuren von höheren Fettsäuren.

Diese beiden jecorinartigen Substanzen haben viel Gemeinschaftliches mit der im I. Teil beschriebenen sirupartigen glykosereichen Substanz.

Aus dem Vergleich aller von mir dargestellten Jecorine könnte man den Schluß ziehen, daß Jecorine mit großem Glykosegehalt einen geringen (oder gar keinen) Fettsäuregehalt, einen kleinen $\mathrm{P}$ - und verhältnismäßig hohen $\mathrm{N}$-Gehalt aufweisen. Der Gehalt an Glykose und ebenso an unorganischen Bestandteilen scheint aber abhängig zu sein von dem Wassergehalt der Extraktionsmittel.

Jecorine mit hohem P-Gehalt und niedrigerem N-Gehal lösen sich viel weniger in Wasser als Jecorine mit hohem N-Gehalt und niedrigem P-Gehalt. Möglicherweise wird die Löslichkeit der Jecorine in Wasser durch den größeren oder geringeren Fettsäuregehalt beinflußt.

Nach dem Abfiltrieren des Niederschlages, der das Jecorin enthielt, wurde die ätherisch-alkoholische Lösung bis zur Trockene 
abgedampft. Der Rückstand wurde in Äther gelöst und durch Aceton gefällt. Es entstand ein gelblich brauner Niederschlag, welcher der Erlandsenschen Fraktion $\delta$ entsprach, d. h. ein Lecithin darstellte. Diese Fraktion enthielt, ebenso wie bei Erlandsen, bei weitem die überwiegende Menge der P-haltigen Substanzen des Alkoholextraktes und war frei von reduzierenden Substanzen. Dieser Niederschlag wurde durch einmaliges Auflösen in Äther und Fällung mit Aceton gereinigt.

Getrocknet stellte es eine klebrige rotbraune Masse dar, die viel dunkler gefärbt war als das Lecithin des Ätherextrakts nach Erlandsen und auch dunkler als das Lecithin, das aus primärem Alkoholextrakt gewonnen wurde (I. Teil). Die P- und N-Bestimmungen des Präparats gaben folgende Resultate:

$$
\mathrm{P}=3,39 \% ; \mathrm{N}=3,91 \% ; \mathrm{P}: \mathrm{N}=1: 2,55 \text {. }
$$

Kjeldahlbestim mung: 0,488 g Substanz gaben $13,7 \mathrm{ccm}$ n/10- $-\mathrm{H}_{8} \mathrm{SO}_{4}$ à $0,0014034 \mathrm{~g}=3,93 \% \mathrm{~N}$.

$0,4749 \mathrm{~g}$ Substanz gaben $13 \mathrm{ccm} \mathrm{n} / 10-\mathrm{H}_{2} \mathrm{SO}_{4}=3,90 \% \mathrm{~N}$.

Neumannbestimmung: $0,1747 \mathrm{~g}$ Substanz gaben $10,7 \mathrm{ccm}$ $\mathrm{n} / \mathbf{2}-\mathrm{NaHO}=3,39 \% \mathrm{P}$.

Erlandsen hat bei derselben Gelegenheit ein Lecithin dargestellt, das folgende Zahlen aufwies:

\begin{tabular}{c|c|c|c}
\hline & $\mathrm{P}$ & $\mathrm{N}$ & $\mathrm{P}: \mathrm{N}$ \\
\hline I. & $3,28 \%$ & $3,63 \%$ & $1: 2,50$ \\
II. & $3,01 \%$ & $3,53 \%$ & $1: 2,59$
\end{tabular}

Aus diesem Lecithin stellte Erlandsen ein Chlorcadmiumlecithinat dar, das $\mathrm{P}=2,62 \% ; \mathrm{N}=2,43 \% ; \mathrm{Cd}=19,08 \%$; $\mathrm{P}: \mathrm{N}: \mathrm{Cd}=1: 2: 2$ enthielt.

Es war also ein Diamidomonophosphatid.

Das von uns dagegen aus unserem Lecithin, nach den Angaben von Erlandsen, dargestellte Chlorcadmiumlecithinat wies folgende Zahlen auf:

$\mathrm{P}=3,18 \% ; \mathrm{N}=2,25 \% ; \mathrm{P}: \mathrm{N}: \mathrm{Cd}=1: 1,57: 1,52$.

Es ist uns also nicht gelungen, wie bei Erlandsen durch 
Cadmiumfällung ein Diamidophosphatid zu bekommen. Jedoch sehen wir deutlich, daß in den sekundären Alkoholextrakt der Pferdeleber, analog den Behauptungen von Erlandsen, Phosphatide übergehen, die einen viel größeren Stickstoffgehalt aufweisen als die Phosphatide des Ätherextraktes und die Phosphatide des primären Alkoholextraktes (I. Teil).

Des Vergleiches halber seien hier die N- und P-Zahlen der Lecithine der Pferdeleber aller 3 Darstellungsmethoden angeführt.

\begin{tabular}{|c|c|c|c|c|c|}
\hline & $\begin{array}{l}\text { Lecithin } \\
\text { aus } \\
\text { primärem } \\
\text { Alkohol- } \\
\text { extrakt }\end{array}$ & $\begin{array}{l}\text { Lecithin } \\
\text { aus } \\
\text { Äther- } \\
\text { extrakt }\end{array}$ & $\begin{array}{l}\text { Lecithin } \\
\text { aus } \\
\text { sekun- } \\
\text { därem } \\
\text { Alkohol- } \\
\text { extrakt }\end{array}$ & $\begin{array}{l}\text { Cadmium- } \\
\text { lecithinat } \\
\text { aus } \\
\text { primärem } \\
\text { Alkohol- } \\
\text { extrakt }\end{array}$ & $\begin{array}{l}\text { Cadmium- } \\
\text { lecithinat } \\
\text { aus } \\
\text { sekundärem } \\
\text { Alkohol- } \\
\text { extrakt }\end{array}$ \\
\hline$\%$ & 3,5 & 4 & 3,39 & 2,85 & 3,18 \\
\hline$\%$ & 2,7 & 1,95 & 3,91 & 1,83 & 2,25 \\
\hline $\mathrm{Cd} \quad \%$ & - & - & - & 14,73 & 17,38 \\
\hline$P: N$ & $1: 1,7$ & $1: 1,1$ & $1: 2,55$ & $1: 1,42$ & $1: 1,57$ \\
\hline $\mathrm{P}: \mathrm{N}: \mathrm{Cd}$ & - & - & - & $1: 1,42: 1,46$ & $1: 1,57: 1,52$ \\
\hline
\end{tabular}

Aus der Tabelle sehen wir, daß im Ätherextrakt ein Monoamidomonophosphatid sich befindet, im sekundären Alkoholextrakt dagegen ein Lecithin, das viel reicher an $\mathrm{N}$ ist (möglich ein Diamidomonophosphatid).

Die N- und P-Zahlen des Lecithins aus primärem Alkoholextrakt stehen in der Mitte zwischen den Zahlen des Lecithins aus Ätherextrakt und des Lecithins aus sekundärem Alkoholextrakt. Daraus kann man schließen, daß bei der direkten Extraktion der Pferdeleber durch Alkohol in den Alkoholextrakt ein Gemenge von Monoamidolecithin und Lecithinen mit höherem N-Gehalt (eventuell Diamidomonophosphatid) übergeht.

Resumé.

Aus den angeführten Ergebnissen kann man den Schluß ziehen, daß das Jecorin, trotz der Behauptungen vieler Autoren, 
die sich mit ihm beschäftigten, doch kein ganz willkürliches Gemenge der Bestandteile, d. h. eines lecithinartigen Komplexes, Glykose, S-haltiger Verbindung und unorganischer Stoffe, darstellt. Vielmehr ist das nach Drechselschen Angaben gereinigte Jecorin, wenn man nur stets acht gibt, daß das Endprodukt nach der Reinigung vollständig ätherlöslich ist, und aus der Lösung quantitativ durch Alkohol sich fällen läßt, eine doch ziemlich konstante Verbindung, wenigstens in bezug auf ihren N-, P- sowie Glykosegehalt.

Zum Vergleich sind hier in der Tabelle die Analysenzahlen aller von mir dargestellten, nach Drechsels Angaben gereinigten, Jecorine angeführt.

\begin{tabular}{|c|c|c|c|c|c|c|c|}
\hline \multicolumn{7}{|c|}{ Jecorine aus Pferdeleber } & \multirow{2}{*}{$\begin{array}{c}\text { Bier- } \\
\text { nadzkys } \\
\text { Jecorin } \\
\text { aus } \\
\text { Knochen- } \\
\text { mark des } \\
\text { Hundes }\end{array}$} \\
\hline & $\begin{array}{l}\text { Jecorin } \\
\text { Nr. I }\end{array}$ & $\begin{array}{l}\text { Jecorin } \\
\text { Nr. II a }\end{array}$ & $\begin{array}{l}\text { Jecorin } \\
\text { Nr. II b }\end{array}$ & $\begin{array}{l}\text { Jecorin } \\
\text { Nr. III a }\end{array}$ & $\begin{array}{l}\text { Jecorin } \\
\text { Nr. IIIb }\end{array}$ & $\begin{array}{l}\text { Jecorin } \\
\text { Nr. IV }\end{array}$ & \\
\hline$\%$ & 3,12 & 2,59 & 2,54 & 2,55 & 2,57 & 2,52 & 2,67 \\
\hline$\%$ & 2,89 & 3,01 & 2,81 & 2,83 & 2,87 & 2,89 & 2,88 \\
\hline$\%$ & 1,82 & $\begin{array}{c}\text { vor- } \\
\text { handen }\end{array}$ & $\begin{array}{c}\text { vor- } \\
\text { handen }\end{array}$ & $\begin{array}{c}\text { vor- } \\
\text { handen }\end{array}$ & $\begin{array}{c}\text { vor- } \\
\text { handen }\end{array}$ & $\begin{array}{c}\text { vor- } \\
\text { handen }\end{array}$ & 1,007 \\
\hline Glykose $\%$ & 14,4 & 14,75 & 14,65 & 14,13 & 14,61 & 14,51 & - \\
\hline Asche $\quad 0 / 0$ & 12,79 & - & - & 一 & - & - & - \\
\hline Fettsäuren $\%$ & 40,75 & 37,85 & $\begin{array}{c}\text { vor- } \\
\text { handen }\end{array}$ & $\begin{array}{c}\text { vor- } \\
\text { handen }\end{array}$ & $\begin{array}{l}\text { vor- } \\
\text { handen }\end{array}$ & $\begin{array}{l}\text { vor- } \\
\text { handen }\end{array}$ & - \\
\hline $\mathrm{P}: \mathrm{N}$ & $1: 2,38$ & $1: 1,905$ & $1: 2,005$ & $1: 2,01$ & $1: 2$ & $1: 1,93$ & $1: 2,04$ \\
\hline
\end{tabular}

Aus der Tabelle sehen wir, daß der N-Gehalt in allen angeführten Jecorinen derselbe ist (im Mittel $=2,55 \%$ ) und ebenso der P-Gehalt (im Mittel $=2,87 \%$ ); das Verhältnis $\mathrm{N}: \mathrm{P}$ ist nahezu $1: 2$; der Glykosegehalt rund $14 \%$.

Das in der Tabelle rechts angeführte Jecorin aus Pferdeknochenmark wurde in demselben Laboratorium, in dem die vorliegende Arbeit vollführt war, von Herrn Magister der Pharm. Biernadsky erhalten und nach den Drechselschen 
Angaben gereinigt. Der N-, P- und S-Gehalt sowie das Verhältnis $\mathrm{P}: \mathrm{N}$ sind in diesem Jecorin dieselben wie bei dem von mir erhaltenen Jecorin.

Ess sei hierbei noch hervorgehoben, daß ich bei meinen Versuchen die Art der Extraktion der Leber und der Darstellungsweise des Jecorins vielfach modifiziert habe und zum Schluß nach der Reinigung immer ein Jecorin von eben derselben Zusammensetzung erhalten habe.

Auf Grund des Gesagten kann man das Drechselsche Jecorin als eine Verbindung des lecithinartigen Komplexes mit ca. $14 \%$ Glykose charakterisieren, die außerdem noch immer Schwefel und eine unorganische Substanz in sich enthält. Der lecithinartige Komplex enthält stets höhere Fettsäuren.

Dem Verhalten P : $\mathrm{N}$ nach ist das Jecorin ein Diamidomonophosphatid im Sinne von Erlandsen.

Freilich, ob das Drechselsche Jecorin von der angegebenen Zusammensetzung im lebenden Organismus als solches vorhanden ist oder ob wir das beschriebene Jecorin dank allen den Manipulationen mit den Lösungsmitteln usw. als Kunstprodukt erhalten hatten, darüber können noch $Z_{w}$ eifel obwalten, und die Lösung der Frage bedarf weiterer zahlreieher Untersuchungen. Das eine kann festgestellt werden, daß das von mir dargestellte Jecorin eine ganz bestimmte Elementarzusammensetzung aufweist und eine ziemlich feste Verbindung darstellt.

Der Grund, daß verschiedene Autoren verschiedene, stark voneinander abweichende Analysenzahlen für die Zusammensetzung der von ihnen dargestellten Jecorine erhalten haben, scheint darin $\mathrm{zu}$ liegen, daß die Darstellungsmethoden der Jecorine verschiedene waren und daß die Reinigung der Produkte (nach Drechselschen Angaben) keine vollständige war. Wir sahen im I. Teil, daß außer dem Endprodukt - reinem Drechselschen Jecorin - andere jecorinartige Produkte existieren, wie das ätherunlösliche Jecorin, das aus dem rohen Jecorin durch Reinigung dem Endprodukte entzogen wurde, und die an Glykose reiche, sirupartige, jecorinähnliche Substanz, welche beide einen vom Drechselschen Jecorin stark ab- 
weichenden N- und P-Gehalt aufwiesen. Bei der Reinigung des Produktes habe ich stets streng darauf geachtet, daß diese beiden jecorinartigen Produkte vom Endprodukt, d. h. dem reinen Jecorin, sorgfältig beseitigt wurden. Bei der Reinigung der Präparate II bis IV wurde die Ätherlösung des Jecorins durch Alkohol gefällt und stets im Becherglase am kühlen Ort einen Tag lang stehen gelassen, am nächsten Tage wurde der Niederschlag wieder in Äther gelöst, durch Alkohol gefällt usw.; bei diesem Verfahren war die Reinigung eine vollkommene.

Was die Erlandsensche Methode der primären Ätherextraktion und sekundären Alkoholextraktion betrifft, so eignet sich diese Methode sehr gut für die Isolierung der verschiedenen Phosphatide voneinander, nicht aber für die Darstellung des Drechselschen Jecorins.

Im Ätherextrakt ist wohl ein Phosphatid - das Heparphosphatid - vorgefunden, das viele mit dem Jecorin gemeinsame Eigenschaften zeigte, sich von demselben aber durch Abwesenheit von Glykose und Natrium, die verschiedenen $\mathrm{P}$ - und $\mathrm{N}-\mathrm{Werte}$ und das verschiedene Verhältnis von $\mathrm{P}: \mathrm{N}$ unterschied.

Im sekundären Alkoholextrakt dagegen wurden zwar jecorinartige Produkte gefunden, es ließ sich aber aus ihnen das Drechselsche Jecorin nicht darstellen.

Am besten eignet sich für die Darstellung des Drechselschen Jecorins die primäre Extraktion der frischen (nicht getrockneten) Leber mit absolutem Alkohol oder die Extraktion der getrockneten Leber mit wasserhaltigem Alkohol. Die weitere Bearbeitung sei auf der folgenden Seite schematisch angeführt.

Beim Innehalten der beschriebenen Darstellungsmethode habe ich in allen Fällen aus verschiedenen Pferdelebern Jecorine erhalten, die stets voneinander nur wenig abweichende Zusammensetzungen aufwiesen, wie es aus der nachfolgenden Tabelle ersichtlich ist. 
Der bis zur Sirupkonsistenz abgedampfte Rückstand des primären Alkoholextrakts wird mit Äther versetzt

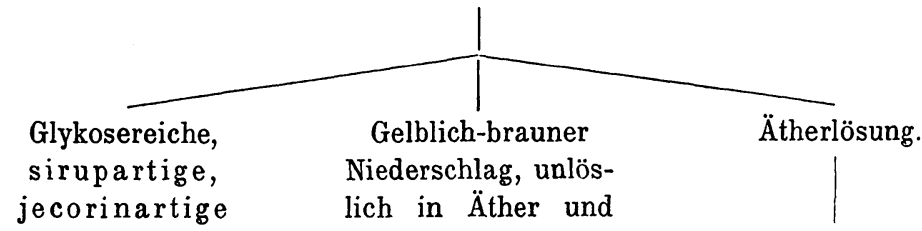

Substanz (als schwere Schicht am Boden des Gefäßes). (I. Teil, II. Versuch.) Alkohol (von mir nicht analysiert).

Niederschlag (meistenteils sirupartig) das rohe Jecorin (siehe I. Teil, Versuch V).
Fällung durch absoluten Alkohol.

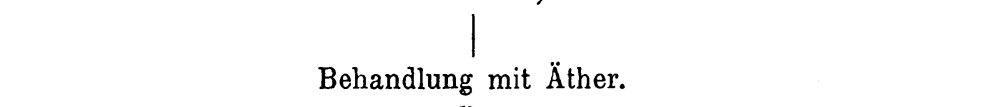

Ätherunlösliche jecorinartige Substanz (siehe I. Teil, V. Versuch).
Ätherlösung, die das Drechselsche Jecorin enthält.

Alkoholfällung; der Niederschlag samt Lösung einen Tag stehen gelassen.

Wiederholen dieser Operation des Auflösens in Äther und Fällen durch Alkohol 3-4mal (Waschen mit Alkohol durch Dekantieren wurde vermieden).

Reines Drechsel'sches Jec orin.

Zum Schluß sei es mir gestattet, der hochgeehrten Frau Dr. med. N. 0. Sieber und dem Assistenten, Herrn W. S. Djersgowsky, meinen aufrichtigen Dank für den mir bei der Ausführung dieser Arbeit geleisteten Beistand zu sagen. 